\title{
Ablation of cyclase-associated protein 2 (CAP2) leads to cardiomyopathy
}

\author{
Vivek S. Peche $\cdot$ Tad A. Holak $\cdot$ Bhagyashri D. Burgute $\cdot$ Kosmas Kosmas $\cdot$ \\ Sushant P. Kale $\cdot$ F. Thomas Wunderlich $\cdot$ Fatiha Elhamine $\cdot$ Robert Stehle \\ Gabriele Pfitzer • Klaus Nohroudi · Klaus Addicks • Florian Stöckigt • \\ Jan W. Schrickel · Julia Gallinger • Michael Schleicher · Angelika A. Noegel
}

Received: 6 June 2012/Revised: 1 August 2012/Accepted: 14 August 2012/Published online: 4 September 2012

(C) Springer Basel AG 2012

\begin{abstract}
Cyclase-associated proteins are highly conserved proteins that have a role in the regulation of actin dynamics. Higher eukaryotes have two isoforms, CAP1 and CAP2. To study the in vivo function of CAP2, we generated mice in which the CAP2 gene was inactivated by a gene-trap approach. Mutant mice showed a decrease in body weight and had a decreased survival rate. Further, they developed a severe cardiac defect marked by dilated cardiomyopathy (DCM) associated with drastic reduction in basal heart rate and prolongations in atrial and
\end{abstract}

Electronic supplementary material The online version of this article (doi:10.1007/s00018-012-1142-y) contains supplementary material, which is available to authorized users.

V. S. Peche · B. D. Burgute · K. Kosmas · A. A. Noegel ( $ه)$

Institute of Biochemistry I, Medical Faculty,

University of Cologne, Joseph-Stelzmann-Str. 52,

50931 Cologne, Germany

e-mail: noegel@uni-koeln.de

V. S. Peche - B. D. Burgute · F. T. Wunderlich

A. A. Noegel

Center for Molecular Medicine Cologne (CMMC),

Cologne Excellence Cluster on Cellular Stress Responses

in Aging-Associated Diseases (CECAD), University of Cologne,

Cologne, Germany

F. Elhamine $\cdot$ R. Stehle $\cdot$ G. Pfitzer

Institute of Vegetative Physiology, University of Cologne,

Cologne, Germany

K. Nohroudi · K. Addicks

Institute of Anatomy I, University of Cologne,

Cologne, Germany

T. A. Holak

Max-Planck-Institute of Biochemistry,

82152 Martinsried, Germany ventricular conduction times. Moreover, CAP2-deficient myofibrils exhibited reduced cooperativity of calciumregulated force development. At the microscopic level, we observed disarrayed sarcomeres with development of fibrosis. We analyzed CAP2's role in actin assembly and found that it sequesters G-actin and efficiently fragments filaments. This activity resides completely in its WASP homology domain. Thus CAP2 is an essential component of the myocardial sarcomere and is essential for physiological functioning of the cardiac system, and a deficiency leads to DCM and various cardiac defects.

Keywords M-line · Filament assembly · WH2 domain · Cardiomyopathy

T. A. Holak

Faculty of Chemistry, Jagiellonian University,

Ingardena 3, 30-060 Krakow, Poland

F. T. Wunderlich

Max-Planck-Institute of Neurological Research,

Cologne, Germany

F. Stöckigt · J. W. Schrickel

Department of Medicine-Cardiology,

University of Bonn, Bonn, Germany

J. Gallinger · M. Schleicher

Institute for Anatomy and Cell Biology,

Ludwig-Maximilians University, 80336 Munich, Germany

S. P. Kale

Department of Neurology, Southern Illinois University School of Medicine, Springfield, IL, USA 


\section{Introduction}

Cardiomyopathy is a disease characterized by either thickening or thinning of the heart muscle, and both conditions, hypertrophic cardiomyopathy (HCM) and dilated cardiomyopathy (DCM), lead to inefficient functioning of the heart muscle and can cause sudden cardiac death. DCM is the most common cardiomyopathy and many studies point out the importance of left ventricular pathophysiology in congestive heart diseases, whereas right ventricular DCM, in which the right ventricle is dilated with thinning of the ventricular wall, is less frequently observed than left ventricular cardiomyopathy and is therefore not extensively studied [1]. In the early 1980s, Fitchett and coworkers [2] described right ventricular DCM in several patients and, moreover, observed a male preponderance in their studies. In many patients, right ventricular DCM was coupled with the occurrence of a dilated right atrium [3]. At the structural level, DCM was associated with a loss of myofibrils and sarcomeric disorganization $[4,5]$. The inherited forms of DCM are associated with mutations in genes that generally encode cytoskeletal and sarcomeric proteins $[1,6]$.

In sarcomeres, the precise control of actin filament length contributes to the proper function of the contractile apparatus. This control appears to occur at the barbed and pointed end of the filament as actin is mainly incorporated at the Z-disc and the middle of the sarcomere (A-band region) where it depends upon effective termination of polymerization by capZ and tropomodulin, respectively [7, 8]. Filament growth is also affected by the G-actin/F-actin equilibrium, which is regulated by G-actin sequestering proteins. Recent studies demonstrated that actin filaments in sarcomeres of actively contracting cells undergo rapid turnover in which actin depolymerizing factors cofilin 1 and 2 are involved which promote rapid actin dynamics [9]. The cyclase-associated protein (CAP) also belongs to the class of G-actin sequestering proteins.

CAP is an evolutionary highly conserved protein comprising 474-551 amino acid residues. In higher eukaryotes, two isoforms are present, CAP1 and CAP2 showing 76\% similarity. CAP consists of an $\mathrm{N}$-domain followed by a proline-rich stretch and a WASP homology (WH2) domain and the actin-binding C-domain. The $\mathrm{WH} 2$ domain is a small motif of approximately 25 amino acids found in different proteins such as WASP (Wiskott-Aldrich Syndrome Protein), thymosin, Spire, Cordon-bleu, Leiomodin, and JMY. These proteins can either sequester monomeric actin or inhibit actin polymerization like thymosin or nucleate actin assembly like Spire, Cordon-bleu, and JMY [10]. WH2 motifs are intrinsically disordered, adopting an $\alpha$-helical structure only upon binding to actin [11]. CAP in lower eukaryotes as well as mouse CAP1 are involved in cell polarity, motility, and receptor-mediated endocytosis [12-14]. Additionally, mammalian CAP1 was shown to be a proapoptotic protein [15].

The Cap 2 gene is expressed at early to late developmental stages during cardiogenesis of mice embryos [16]. We previously reported that in contrast to the broadly expressed CAP1, CAP2 is significantly expressed only in brain, heart, skeletal muscle, and skin. In keratinocytes and in undifferentiated myoblasts, CAP2 localizes to the nucleus, and in differentiated myotubes it is present at the M-line. CAP1 is present on stress fibers and in F-actin-rich regions [17].

Although various studies implicate the role of CAPs in the organization of the actin cytoskeleton, a detailed analysis of the in vivo function of CAP is still lacking. Here we report a mouse in which the Cap 2 gene is inactivated by a gene-trap approach. Our results show that ablation of CAP2 leads to severe cardiac defects marked by dilated cardiomyopathy associated with a drastic reduction in basal heart rate and prolongations in atrial as well as ventricular conduction times. Moreover, we found alterations in the mechanical properties of the CAP2-deficient myofibrils with a significantly reduced Hill coefficient and severe changes in the structure of the sarcomere. As the underlying mechanism, we propose a misregulation of actin filament assembly near the M-line due to the absence of CAP2.

\section{Materials and methods}

Generation of Cap2 $2^{\mathrm{gt} / \mathrm{gt}}$

Clone D07 was obtained from the EUCOMM consortium, Helmholtz Zentrum München, Munich, Germany. ES cells were microinjected into blastocysts and chimeras were produced. The generated chimeric males were then intercrossed with C57BL/6N females to generate F1 offspring. The Cap $2^{g t}$ allele was detected by BamHI digestion of genomic DNA and Southern blotting by using probes generated by using primers pairs; forward-probe $5^{\prime}$-GGAAAACCTGTTGAAGGCAG$3^{\prime}$ and reverse-probe $5^{\prime}$ CCCTGAACTG AGAATGTTCC- $3^{\prime}$. PCR primers for genotyping were:

Forward-Cap2: 5'GTGCTTCACTGATGGGCTTG3'

Reverse-Cap2: 5'TCACCCCACATTTACGATGG3'

Forward-neo: 5'GCCGCTCCCGATTCGCAG3'

Additionally, heterozygous Cap2 gene-trap mice were obtained from the EUCOMM consortium, Helmholtz Zentrum München, Munich, Germany. These mice were maintained in the C57BL/6 background.

Immunohistochemistry, antibodies, and histology

Heart tissue was fixed in $4 \%$ paraformaldehyde, embedded in paraffin, and sectioned. Incubation was with primary 
mouse-monoclonal antibodies (mAb) specific for desmin, alpha-actinin, troponin-I, connexin 43, and rabbit polyclonal antibodies specific for myomesin (all from Sigma), rabbit $\mathrm{mAb}$ antibodies against cleaved caspase 3 (Cell Signaling Technology, Beverly, MA, USA) and incubated with secondary antibodies (Invitrogen-Molecular Probes, Carlsbad, CA, USA) for $1 \mathrm{~h}$. Nuclei were visualized with $4^{\prime}, 6^{\prime}$-Diamidino-2'-phenylindole (DAPI). Sections were mounted and imaged with a Leica confocal microscope. LacZ staining was performed as described [18]. H\&E staining was performed according to the standard procedures. Masson's trichrome staining to detect fibrosis was performed according to the manufacturer's protocol (Sigma).

RNA isolation and quantitative real-time PCR (qRT-PCR)

Hearts were dissected from 6 to 8 -week-old WT and $\mathrm{Cap}^{g t / g t}$ mice ( $n=5$ for each group) and immediately frozen in liquid nitrogen. Tissues were homogenized with an ULTRA TURRAX (IKA Labortechnik, Staufen, Germany) and RNA was isolated using Qiagen RNA isolation kit (Qiagen, Hilden, Germany). Quantity and quality of RNA was analyzed on an Agilent Bioanalyser (Agilent Technologies). cDNA was prepared by reverse transcription of $2 \mu \mathrm{g}$ RNA using the Transcriptor High fidelity cDNA synthesis Kit (Roche, Germany). Real time PCR was carried out with the Opticon III instrument (MJ Research) using the Quantitect ${ }^{\mathrm{TM}}$ SYBR ${ }^{\circledR}$ green PCR kit (Qiagen, Hilden, Germany). For every cDNA quantification, three reactions were performed in parallel per animal, quantification results were normalized with the GAPDH control and mean values were calculated. q-PCR primers used for ANP and BNP were ANP-Fp: $5^{\prime}$-TG CCGGTAGAAGATGAGGTC-3', ANP-Rp:5'-AGCAGCT GGATCTTCGTAGG-3' ${ }^{\prime}$ and BNP-Fp:5'-CAGCTCTTGA AGGACCAAGG-3', BNP-Rp:5'-AGAGACCCAGGCAG AG TCAG-3'. Northern blot was done as previously described [17].

\section{Western-blot analyses}

Tissues were homogenized and lysed according to [17]; proteins were resolved on polyacrylamide SDS gels, transferred to nitrocellulose membranes, and then subjected to immunolabeling. Primary antibodies used were polyclonal antibodies (pAb) against CAP1 and CAP2 [17] and $\mathrm{mAb}$ against $\beta$-actin (Sigma, St. Louis, MO, USA). Horseradish peroxidase conjugated secondary antibodies were used for detection.

Expression of CAP2 domains and in vitro assays

N-CAP2WH2 (aa 1-310), WH2-CCAP2 (aa 247-476), $\triangle \mathrm{WH} 2-\mathrm{CCAP} 2$ (aa 310-476), and WH2 (aa 247-310) encoding sequences were cloned into pGEX 4T-3 expression vector, proteins were expressed, purified and the GST moiety was removed by thrombin cleavage. Actin purification, labeling, and fluorescence measurements were carried out using procedures described previously [10].

Interaction of the $\mathrm{WH} 2$ domain and actin

Actin polymerization was analyzed on a LS-50 Perkin Elmer fluorometer using pyrenylated rabbit skeletal muscle actin essentially as described by [19]. Fluorescence microscopy data were acquired on a Zeiss LSM 510 confocal microscope. Actin was labeled with the amine-reactive dye Alexa Fluor 488 carboxylic acid succinimidyl ester (Invitrogen) essentially as described by [20]. Labeled actin $(5 \mu \mathrm{M})$ was prepolymerized for $60 \mathrm{~min}$, diluted to $1 \mu \mathrm{M}$ in polymerization buffer, and subsequently bundled by the addition of $0.3 \mu \mathrm{M}$ human fascin. Using two Teflon spacers $(20 \times$ $0.5 \mathrm{~mm}$ ) and a normal $18 \times 18 \mathrm{~mm}$ coverslip, a flow chamber was mounted on a $50 \times 50 \times 0.16-\mathrm{mm}$ glass slide that was coated with nitrocellulose $(0.1 \%$ collodion-solution in isoamyl alcohol). The resulting chamber was floated with $0.1 \mu \mathrm{g} / \mu \mathrm{l}$ NEM-HMM in NEM-buffer $(2.5 \mathrm{mM}$ imidazole (pH 7.4), $440 \mu \mathrm{M} \mathrm{MgCl}_{2}, 100 \mu \mathrm{M}$ EGTA, $30 \mu \mathrm{M} \mathrm{KCl}$ ) for $3 \mathrm{~min}$ and then washed with polymerization buffer. The buffer was replaced by an appropriate dilution of the actinfascin mixture and the bundles were allowed to bind to the NEM-HMM for $10 \mathrm{~min}$. After removal of unbound actin bundles with polymerization buffer, the chambers were ready for addition of $\mathrm{WH} 2$ solutions. Usually, the area of interest was scanned $4 \times$ per frame at a frame rate of $1 \mathrm{~s}$.

\section{Electron microscopy}

For electron microscopy, the pieces of heart tissue were quickly immersed in glutaraldehyde and cut into $1-\mathrm{mm}^{3}$ cubes. Thereafter, the tissue was fixed for $2 \mathrm{~h}$ in a solution of $2 \%$ glutaraldehyde in $0.1 \mathrm{M}$ sodium cacodylate buffer $(\mathrm{pH}=7.4)$ at $4{ }^{\circ} \mathrm{C}$. The tissue was then thoroughly washed three times in $0.1 \mathrm{M}$ sodium cacodylate buffer and postfixed in $1 \%$ OsO4 in $0.1 \mathrm{M}$ sodium cacodylate buffer for $2 \mathrm{~h}$ at $4{ }^{\circ} \mathrm{C}$. After the repeated washing, the tissue was dehydrated in graded alcohols and embedded in Epon 812. The blocks were cut on an Ultramicrotome (UltraCut UC-6, Leica, Wetzlar, Germany). Ultrathin sections were routinely contrasted with uranyl acetate and lead citrate. The material was examined with a Zeiss EM-902 electron microscope (Carl Zeiss, Oberkochen, Germany).

\section{Surface ECG}

Surface ECG was recorded of 17 mice (nine WT and eight Cap2 $\left.{ }^{\mathrm{gt} / \mathrm{gt}}\right)$ at the age of 14 weeks. All recordings were 
performed under inhalation anesthesia (induction period 2.5 vol. $\%$, maintenance 1.2 vol. $\%$ isoflurane in $70 \%$ $\mathrm{N}_{2} \mathrm{O} / 30 \% \mathrm{O}_{2}$ ). A surface six-lead ECG was monitored continuously and standard ECG parameters were analyzed under stable baseline conditions. All data were amplified, filtered, sampled at $4 \mathrm{kHz}$, and digitally stored (LabSystem, C.R. Bard Inc., New Jersey, USA). The frequencycorrected QT time (QTc) was calculated according to [21].

Steady-state force and kinetic force measurement in myofibrils

Subcellular myofibrils were isolated from Triton-X100 skinned papillary muscles of right and left ventricles from
Cap2 $2^{g t / g t}$ and WT mice. Myofibrillar force was measured using an atomic force cantilever and the rapid solution change technique described in [22]. Solutions used in force measurements contained $10 \mathrm{mM}$ imidazole, $1 \mathrm{mM} \mathrm{K} \mathrm{K}_{2} \mathrm{Cl}_{2}$ $\mathrm{Na}_{2} \mathrm{Mg}$-ATP, $3 \mathrm{mM} \mathrm{MgCl}_{2}, 47.7 \mathrm{mM} \mathrm{Na}{ }_{2} \mathrm{CrP}, 2 \mathrm{mM}$ dithiothreitol, and either $3 \mathrm{mM} \mathrm{K} \mathrm{K}_{4} \mathrm{Cl}_{2}$-EGTA (relaxing solution) or $3 \mathrm{mM} \mathrm{K} \mathrm{Cl}_{2} \mathrm{Ca}-\mathrm{EGTA}$ (activating solution), adjusted to $\mathrm{pH} 7.0$ at $10{ }^{\circ} \mathrm{C}$ as previously described [22, 23 ]. Solutions containing different activating $\left[\mathrm{Ca}^{2+}\right]$ were produced by mixing relaxation and activating solution at the appropriate ratios. Experiments were performed at $10{ }^{\circ} \mathrm{C}$. Briefly, the myofibril (size: $1.8-5 \mu \mathrm{m}$ in diameter and 34-62 $\mu \mathrm{m}$ in length) was mounted in relaxing solution between a stiff micro-needle and the tip of an atomic force
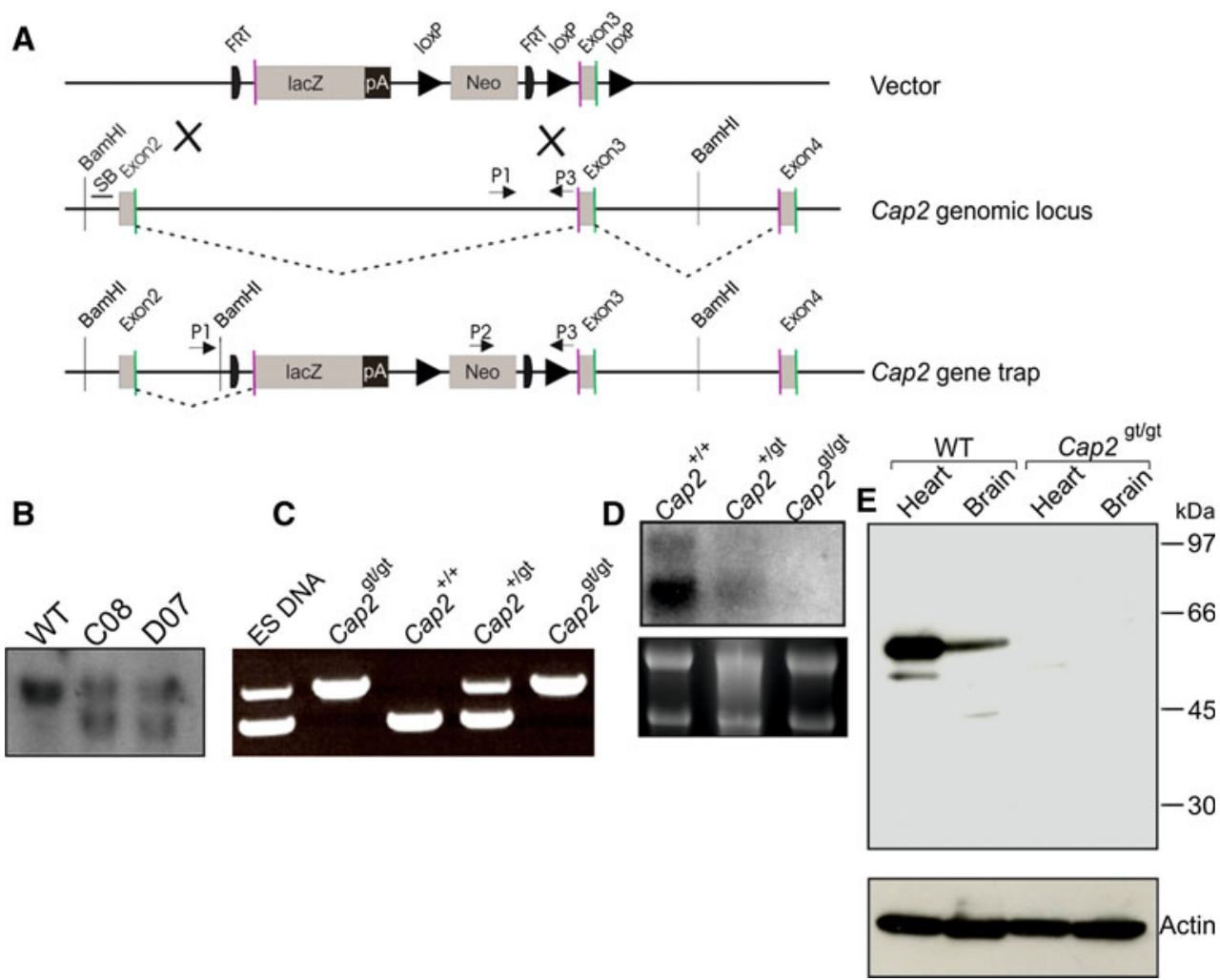

Fig. 1 a-e Targeting strategy for $C a p 2^{g t / g t}$ generation. Schematic representation of CAP2 targeting. a The knockout vector consists of the lacZ gene as a reporter and the neomycin phosphotransferase gene. Genomic locus of the Cap2 gene depicting exon 2, 3, and 4. Transcripts initiated at the endogenous promoter are spliced from the splice donor (green) of an endogenous exon (exon 2 and exon 3 ) to the splice acceptor (purple) of endogenous exons (exon 3 and exon 4). Homologous recombination gave rise to a gene trap of CAP2 $\left(3^{\prime}\right.$ LoxP missed). Transcripts shown as gray dotted line initiated at the endogenous promoter are spliced from the splice donor of an endogenous exon 2 and the splice acceptor of lacZ cassette (diagram not drawn to scale). P1, P2, and P3 are the primers used for genotyping of mice. b Southern-blot analysis of Bam HI digested genomic DNA. Hybridization of radioactively labeled CAP2 probe results in detection of the $10-\mathrm{kb}$ fragment of the WT genomic locus. After the homologous recombination event, hybridization gives rise to an additional fragment of $8 \mathrm{~kb}$. c PCR analysis for genotyping. PCR was performed using primers mentioned in the Materials and methods section for genotyping the animals. The WT allele gives a product of $\sim 550 \mathrm{bp}(\mathrm{P} 1$ and $\mathrm{P} 3)$ while the mutant allele gives a product of $\sim 800 \mathrm{bp}$ (P2 and P3). d Northern-blot analysis. $10 \mu \mathrm{g}$ of RNA from hearts of WT, Cap2 $2^{g t /+}$ and $C a p 2^{g t / g t}$ was separated on a $1 \%$ agarose gel in the presence of formaldehyde $(6 \%)$. The resulting blot was probed with a probe corresponding to nucleotides 1-671 of the mouse CAP2 cDNA. e Western-blot analysis using WT and Cap $2^{g t / g t}$ heart and brain lysates. Proteins of heart and brain lysates were separated on SDS-PA gels (10\% acrylamide) and transferred onto a nitrocellulose membrane. The blots were probed with anti-CAP2 polyclonal antibodies. No protein was detected in $\mathrm{Cap}^{g t / g t}$ while in WT lysates the protein was detected at $\sim 56 \mathrm{kDa}$. Actin was used as a control 
cantilever. After mounting, slack sarcomere length $\left(\mathrm{SL}_{0}\right)$ was determined in relaxing solution. Prior to activation, all myofibrils were stretched to a sarcomere length (SL) of $2.3 \mu \mathrm{m}$. Then, $\mathrm{Ca}^{2+}$-activated force development kinetics and force relaxation kinetics were induced by rapidly (within $10 \mathrm{~ms}$ ) switching from relaxing to activating solution and switching back to relaxing solution using a microflow technique [22]. Statistical analysis was performed by subjecting the data to Student's $t$ test. Statistical significance is denoted by $*$ for $p<0.05$, and $* *$ for $p<0.01$. All values are given as mean \pm SEM (standard error of the mean) of $n$ myofibrils from three mice from each group.

\section{Results}

Generation of a CAP2 knockout mouse

To generate mice lacking the Cap2 gene, we used targeted ES cells (JM8.N4) containing an insertional gene trap which were obtained from the EUCOMM consortium, Helmholtz Zentrum München, Munich, Germany. ES cell clone D07, which was used in this study, represented a gene-trap that could terminate the transcription of the endogenous gene through altered splicing (Fig. 1a). The gene-trap (gt) cassette was inserted in intron 2 of the mouse Cap2 gene on chromosome 13. Alternative splicing of the Cap2 ${ }^{\mathrm{gt}}$ allele generates a new transcript that is a fusion of exon 2 and the LacZ reporter. The fusion protein encodes the first 40 amino acids of CAP2, which are unlikely to show any function mediated by full-length CAP2. We confirmed clones carrying the homologous recombination event with Southernblot analysis in which we detected an additional band of $8 \mathrm{~kb}$ representing the mutant allele (Fig. 1b).

We obtained $\mathrm{Cap}^{\mathrm{gt} / \mathrm{gt}}$ mice by mating $\mathrm{Cap} 2^{+/ \mathrm{gt}}$ male and $\mathrm{Cap} 2^{+/ \mathrm{gt}}$ female from clone D07. Additionally, we also obtained $\mathrm{Cap}^{+/ \mathrm{gt}}$ male and $\mathrm{Cap} 2^{+/ \mathrm{gt}}$ female, which were generated from a different gene-trap clone (B08) at EUCOMM, Munich, Germany. PCR on genomic DNA from tail biopsies was performed with animals, which confirmed the genotype of Cap $2^{\mathrm{gt} / \mathrm{gt}}$ mice showing a single band of $800 \mathrm{bp}$ (Fig. 1c). All phenotypes were confirmed with both mouse lines obtained from the two independent clones. We also carried out Northern-blot analysis to confirm the mutant and to rule out any possibility of generation of aberrant transcripts. An N-terminal probe (1-671 bp of Cap2 cDNA) showed the expected transcripts at 3.6 and $3.2 \mathrm{~kb}$ in $\mathrm{WT}$ as previously reported [17]. The amounts were reduced in $\mathrm{Cap} 2^{\mathrm{gt} /+}$ mice and no transcripts were observed in Cap $2^{\text {gt/gt }}$ mice (Fig. 1d). The successful inactivation of the Cap2 gene was confirmed by Westernblot analysis where we probed heart and brain lysates obtained from $\mathrm{Cap} 2^{\mathrm{gt} / \mathrm{gt}}$ mice and their wild-type (WT) littermates with CAP2-specific polyclonal antibodies [17]. In lysates from WT brain and heart, a signal at $\sim 56 \mathrm{kDa}$ was detected; no protein was seen in lysates from Cap2 $2^{\mathrm{gt} / \mathrm{gt}}$ mice (Fig. 1e). When we probed the blot for expression of CAP1, we did not detect significant up-regulation upon loss of CAP2 excluding the possibility that CAP1 compensates for the deficiency (data not shown).

CAP2 deletion leads to weight loss and is lethal in postnatal stages of mice

The notion that the size of Cap $2^{\text {gt/gt }}$ mice at birth appeared smaller prompted us to follow the body weight. An average weight reduction of approximately 30-40\% was consistently observed in mutant females (Fig. 2a, b). CAP2 deficiency appears to manifest shortly after birth, as during development there was no significant difference in the size of the embryos (data not shown). For male mice, we also noted a lower body weight with an average weight reduction of 40-45\% compared to their WT littermates (Fig. 2c, 40 days of age, $n=8$ ). The survival rates in the $\mathrm{Cap} 2^{\mathrm{gt} / \mathrm{gt}}$ mice differed from the one in WT mice and Cap2 $2^{\mathrm{gt} / \mathrm{gt}}$ died earlier. This phenotype was more drastic in males compared to females as 25 out of $40 \mathrm{Cap}^{\mathrm{gt} / \mathrm{gt}}$ males died between 1 and 70 days after birth. The remaining 15 animals were still alive after 70 days (Fig. 2d). Analyses of $\mathrm{Cap}^{\mathrm{gt} / \mathrm{gt}}$ embryonic stages revealed that mutant mice did not die during embryogenesis. This was also underlined by the Mendelian ratio in which the animals were born $(25 \%$ $\left.\mathrm{WT}, 50 \% \mathrm{Cap}^{+/ g t}, 25 \% \mathrm{Cap}^{\mathrm{gt} / \mathrm{gt}}\right)$.

Cap2 $2^{g t / g t}$ mice exhibit ventricular dilation and a dilated atrium

To determine the cause of death, we focused on the analysis of the hearts from Cap2 ${ }^{\mathrm{gt} / \mathrm{gt}}$ mice and their WT littermates. We first probed the expression of CAP2 in the whole heart by taking advantage of the gene trap, which allowed us to follow the expression of the $\beta$-galactosidase fusion protein derived from the $\mathrm{Lac} Z$ reporter. We used hearts from 30-day-old Cap2 $2^{+/ g t}$ mice and detected X-Gal staining in both atria and ventricles indicative of CAP2 expression (Fig. 3a). At the protein level, we found that it was expressed equally in both ventricles and both atria in WT (data not shown).

Next, we analyzed the hearts and observed an increase in size in the knockout animals with a severe dilation of both ventricle and right atrium (Fig. $3 \mathrm{~b}$ and c). When we compared the hearts from 13-month- old mice, we observed that all four chambers were severely dilated and the size of the heart was drastically increased in Cap $2^{\mathrm{gt} / \mathrm{gt}}$ mice compared to their WT littermates (Fig. 3d). 
Fig. 2 a-d Inactivation of Cap2 leads to weight loss and reduced survival. a Overall appearance of WT and Cap $2^{g t / g t}$ mice aged 40 days. Reduced body length and leanness can be seen in $\mathrm{Cap}^{\text {tt/gt }}$ mice.

b, $\mathbf{c}$ Body weight of mice of different genotypes and gender shows a reduction for $\mathrm{Cap} 2^{g t / g t}$ mice (WT/Cap $2^{\text {gt/gt }}$ females: $n=5 / 8$, WT/Cap2 $2^{g t / g t}$ males: $n=7 / 7)$. d Percent survival versus age in days for WT (male + female, $n=86$ ) versus Cap $2^{\text {gt/gt }}$ female $(n=47)$ and Cap2 ${ }^{\text {gt/gt }}$ male $(n=32)$ mice. $70+$ days survival was monitored in $\mathrm{Cap}^{g t / g t}$ female and $C a p 2^{g t / g t}$ male. Only $40 \%$ Cap2 $2^{g t / g t}$ male and $87 \%$ of Cap2 $2^{\text {gt/gt }}$ female survived over 70 days in comparison to WT animals (99\% survival)

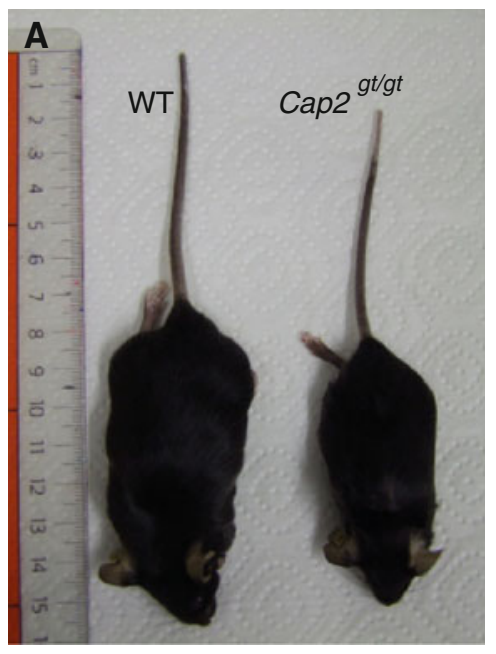

B
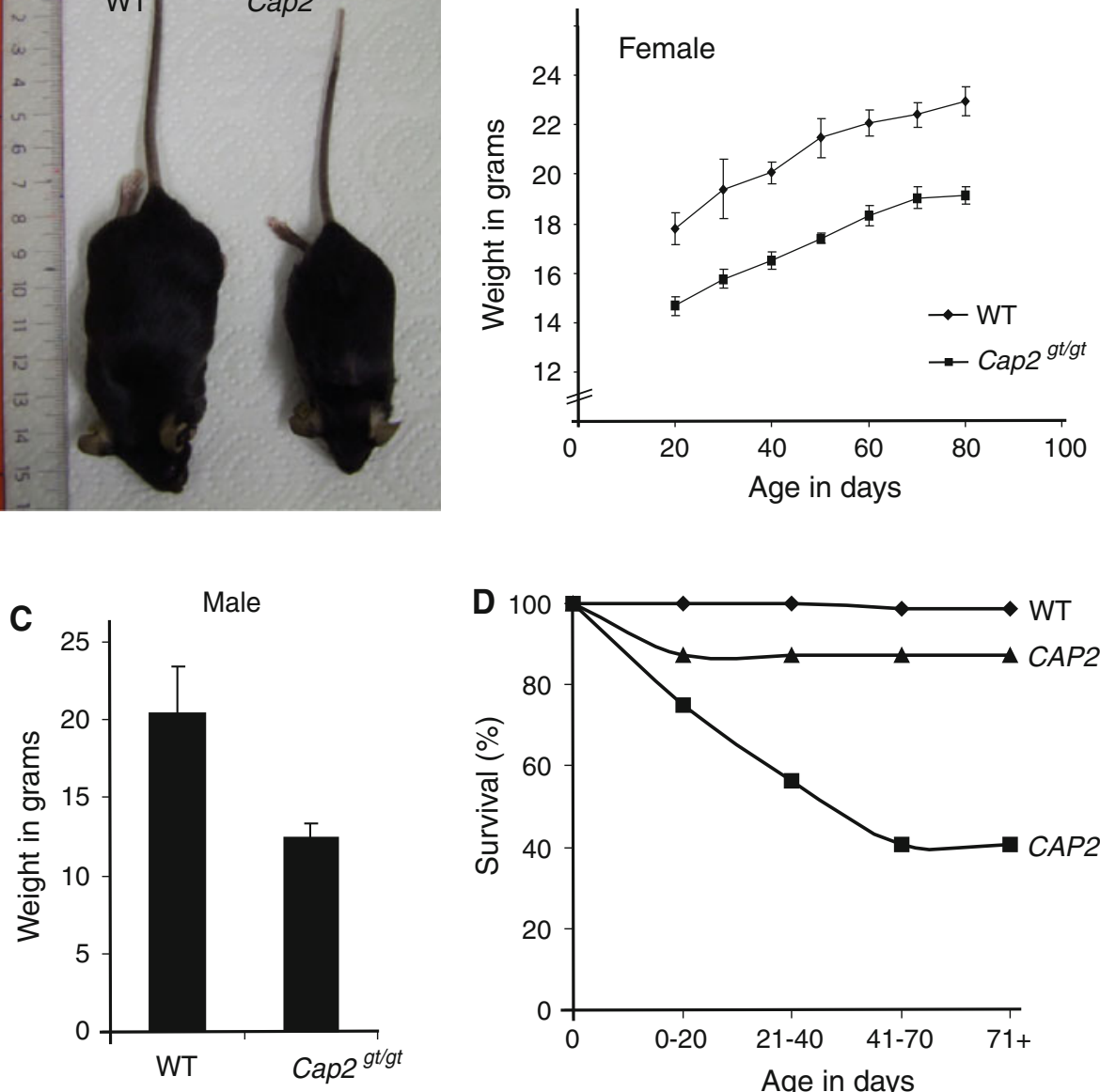

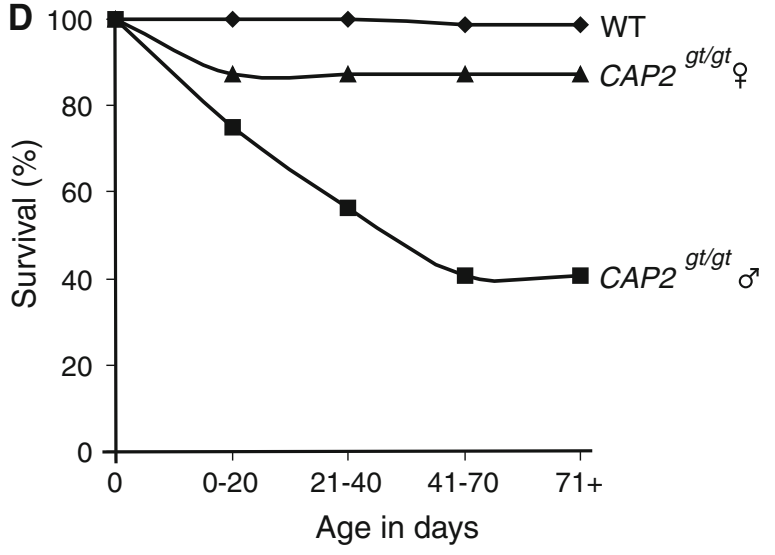

Cardiomyopathy is accompanied by the reactivation of fetal cardiac gene expression like the up-regulation of atrial and brain natriuretic peptides, ANP and BNP. We assessed the levels of the peptides by quantitative real-time PCR and found in Cap2 ${ }^{\text {gt/gt }}$ mice aged 6-8 weeks that the levels of ANP were increased by $\sim 3$-fold and BNP $\sim 4$-fold as compared to age matched WT, indicating the development of cardiomyopathy (Fig. 3e).

Cap $2^{g t / g t}$ mice develop dilated cardiomyopathy

So far, we understood that the loss of CAP2 leads to cardiac dilation, in the following we examined the consequences of the deletion of CAP2 in detail. For both sexes, we observed a reduction in weight at any given time point. The animals were fertile and female mice showed a life span up to 12-14 months $(n=24)$ after which survival decreased rapidly. Autopsy revealed gross morphological differences between $\mathrm{Cap} 2^{\mathrm{g} / \mathrm{gt}}$ and their control littermates. Cap2 $2^{\mathrm{gt} / \mathrm{gt}}$ male and female hearts were characterized by drastic enlargement of ventricles, which was consistently observed in all mice from 40 days onwards. Interestingly, all of the
$\mathrm{Cap} 2^{\mathrm{g} t / \mathrm{gt}}$ mice that died between P1 and P70 also showed an enlarged right and left ventricle. H\&E staining of cardiac sections confirmed the dilation of the ventricles (Fig. 4a-d; Table 1). Consequently, the total area of the right ventricular chamber was also increased significantly in $\mathrm{Cap} 2^{\mathrm{gt} / \mathrm{gt}}$ mice (Fig. 4e). In addition, we noticed a thinning of the ventricular myocardium compared to the total area (Fig. 4f).

Dilated cardiomyopathy is often associated with abnormalities in electrical conductivity of the heart. To check conductivities in mutant hearts, we performed surface electrocardiography (Table 2). Nine WT (five male, four female) and eight mutant (four male, four female) animals were used in surface ECG recordings. The surface ECG showed a significantly decreased heart rate in $\mathrm{Cap}^{\text {gt/ }}$ ${ }^{g t}$. With decelerated heart rate, we also observed a significantly prolonged $\mathrm{PQ}$ interval at equal $\mathrm{P}$-wave length in Cap $2^{g t / g t}$ mice, which can be attributed to negative dromotropic effects correlated with slower heart rate. In the Cap $2^{g t / g t}$ mice, the parameters for atrio-ventricular conduction time (PQ time) as well as intraventricular conduction times (QRS time and QT time) showed marked 

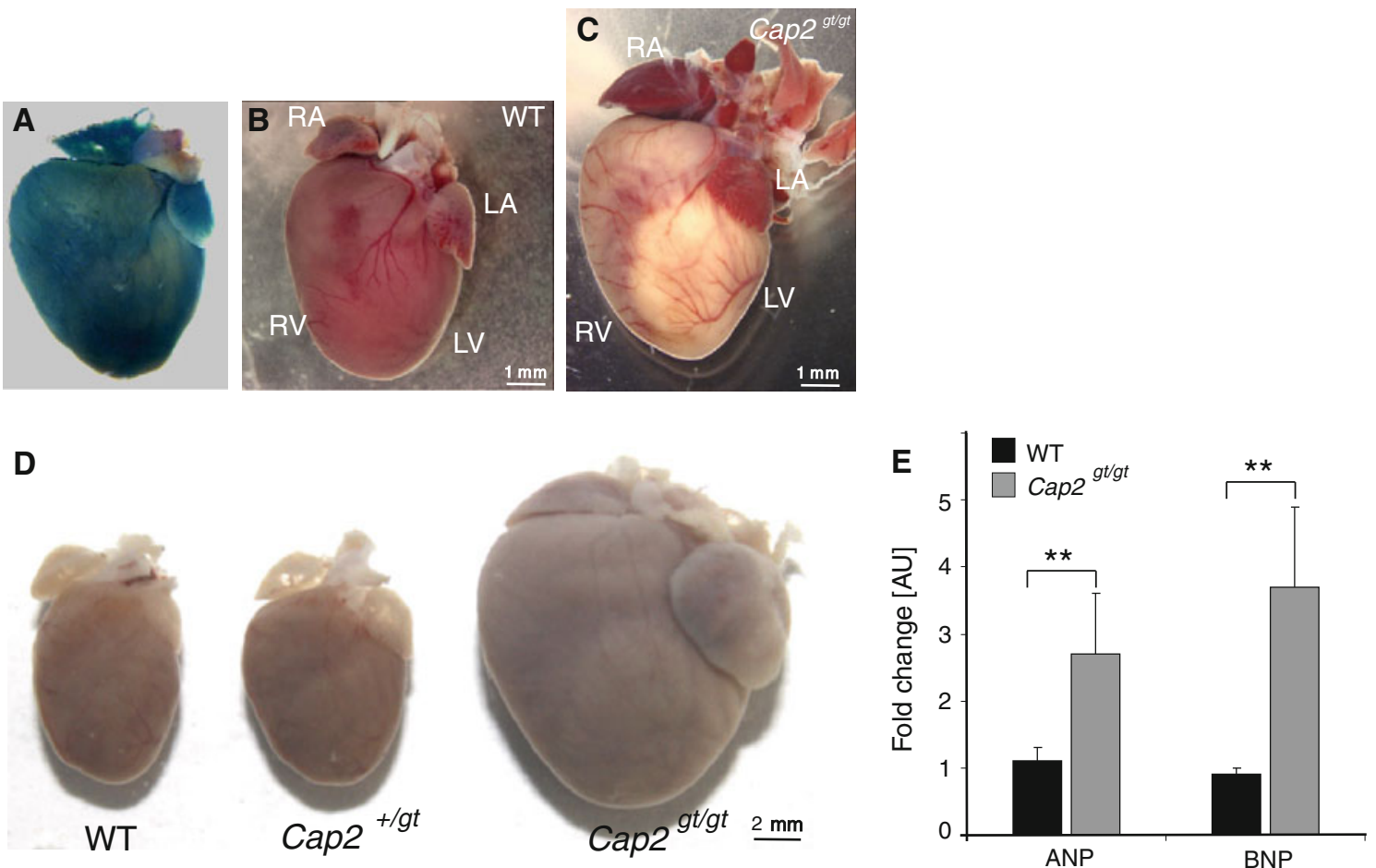

Fig. 3 a-e Cardiac phenotype in $C a p 2^{g t / g t}$ mice. a X-gal staining of Cap2 $2^{+/ g t}$ at P40 demonstrated strong Cap2 expression in all four chambers of the heart. b-d Macroscopic analysis of hearts from 6-week-old male WT (b), Cap2 $2^{g t / g t}$ (c), and 13-month-old female WT, Cap2 $2^{+/ g t}$ and $\mathrm{Cap}^{\text {gt/gt }}$ mice (d) revealed an enlarged heart with dilated right atrium in mutant animals. Mild dilation is observed in

prolongations compared to WT (Table 2; Fig. 4g). After correction for the heart rate, the QTc did not differ between the groups.

Proliferation of interstitial fibroblasts and biosynthesis of extracellular matrix components in the heart are defined as cardiac fibrosis. It is a consequence of remodeling processes initiated by pathologic events associated with a variety of cardiovascular disorders, which leads to abnormal myocardial stiffness and, ultimately, ventricular dysfunction [24]. Staining with Masson's trichrome on transverse cardiac sections of 2-month-old mice revealed no symptoms of fibrosis in $\mathrm{Cap}^{\text {gt/gt }}$ mice (data not shown), but at the age of 6 months we could clearly observe fibrosis in the ventricles of $\mathrm{Cap}^{\mathrm{gt} / g t}$ mice whereas this was not the case in their WT littermates (Fig. 4h). As an increase in fibrosis might be associated with increased apoptosis, we performed caspase 3 staining on cardiac sections (three male, one female; $2-6$ months old) and found that mutant myocardium had significantly higher numbers of apoptotic cells than WT (WT, $0.12 \%$ cells; Cap2 $2^{g t / g t}, 0.94 \%$ cells; $p<0.0005$ ). Also, caspase 3-positive cells were not restricted to any particular region of the myocardium (Fig. 4k). In general, apoptosis was more prominent in failing hearts. heterozygous animals. e Quantitative RT-PCR analysis of cardiomyopathy markers. RNA from WT and $C a p 2^{g t / g t}$ mice $(n=5)$ was used for quantitative RT-PCR analysis of ANP and BNP amount. Fold change was calculated and means were analyzed for statistical significance

To investigate embryonal heart development and the possibility of development of cardiomyopathy/cardiac defects during embryogenesis, embryos between E11-E15 were studied. Whole-mount analysis revealed that embryos did not show obvious external abnormalities. Similar to their WT littermates, at E13.5 cardiac chamber formation was observed in $\mathrm{Cap}^{\mathrm{gt} / \mathrm{gt}}$ mice (Fig. 4i). The cardiac ventricular walls of the Cap $2^{\mathrm{g} t / \mathrm{gt}}$ were slightly thinner than those of the control embryos; the ventricular myocardium of control and $\mathrm{Cap}^{\mathrm{gt} / \mathrm{gt}}$ appeared normal (Fig. 4i). Thus, overall heart development appeared to be not severely affected during embryogenesis of $\mathrm{Cap}^{\mathrm{gt} / \mathrm{gt}}$ mice. At age $\mathrm{P} 4$, mutant hearts exhibited dilated atria and mildly dilated ventricles (Fig. 4j). This underlines our previous finding that CAP2 is expressed in all four chambers and is responsible for physiological functioning of the atria and ventricles, which ultimately govern the heart performance.

CAP2 is required for proper sarcomeric organization in cardiac tissue

We have previously shown that CAP2 is primarily located at the M-band of the sarcomere accompanied by fine striations on either side of the M-band [17]. We performed 
A

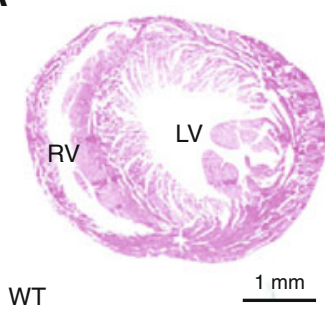

B

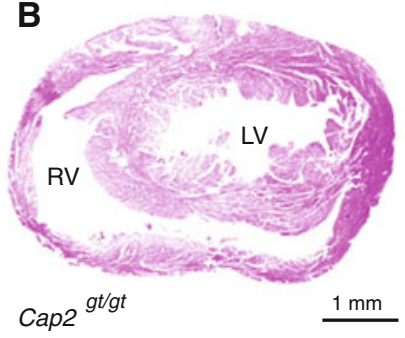

C

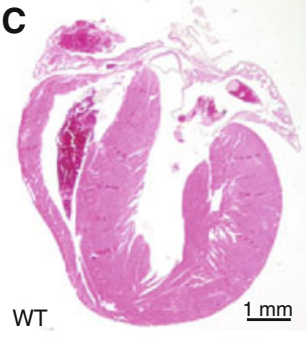

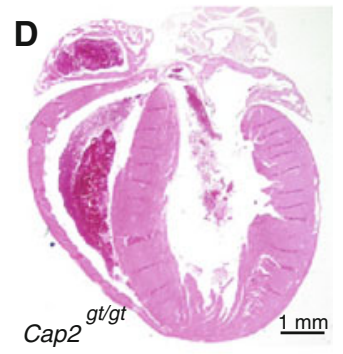
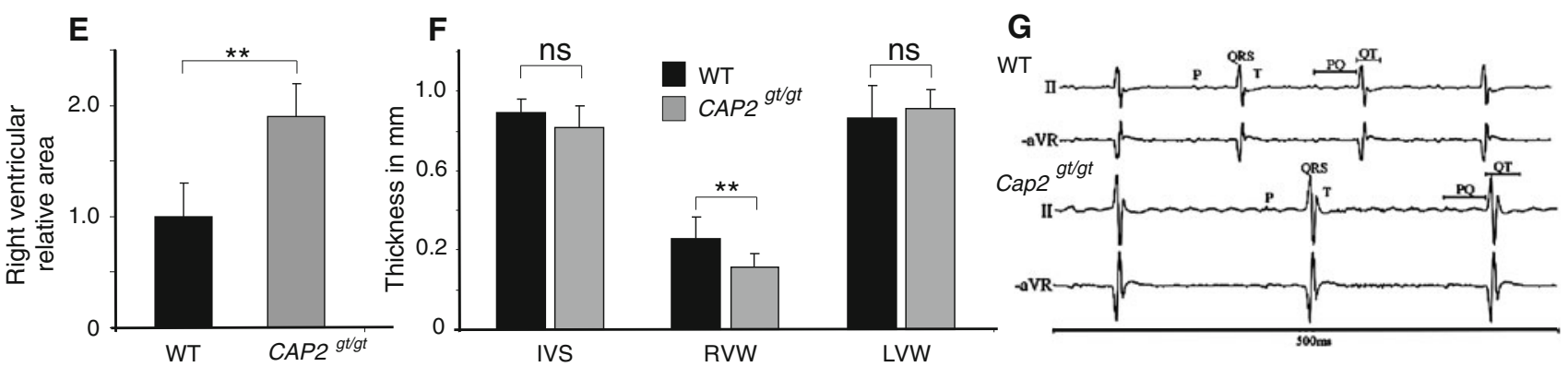

H

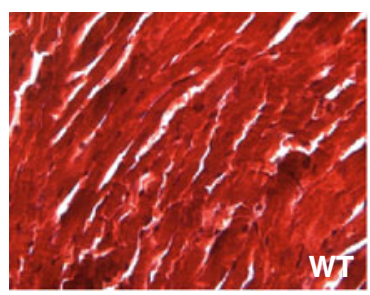

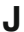

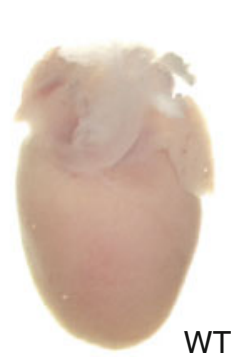

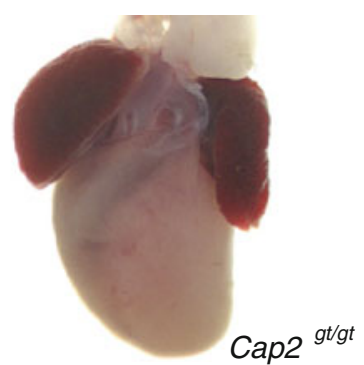

Fig. 4 a-k Characterization of cardiac phenotypes of $\mathrm{Cap}^{\mathrm{gt} / \mathrm{gt}}$ mice. Histological analyses of 2-month-old mice. Representative images of transverse $(\mathbf{a}, \mathbf{b})$ and longitudinal $(\mathbf{c}, \mathbf{d})$ sections of WT and Cap $2^{g t / g t}$ mice stained with H\&E. The mutant exhibited an enlarged ventricular chamber. Scale bars $1 \mathrm{~mm}$. e The relative right ventricular area was also increased in $C a p 2^{g t / g t}$ mice as compared to their WT littermates. f Mean parameters for both genotypes were compared from respective longitudinal sections (IVS, inter-ventricular septum; RVW, right ventricular free wall; LVW, left ventricular wall). Each bar represents the mean \pm SEM from four to five animals. $g$ A representative

immunofluorescence studies to investigate the effect of CAP2 inactivation on sarcomeric organization. In wildtype cardiac tissue, we observed well-formed regular sarcomeres, whereas for cardiac sections derived from $\mathrm{Cap}^{\mathrm{gt} / \mathrm{gt}}$ animals, we observed a mixed sarcomeric organization.

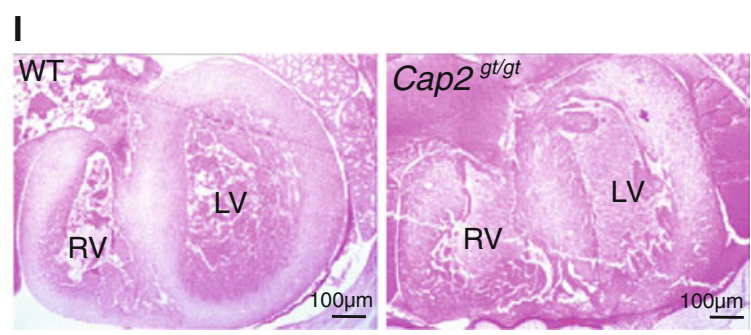

K
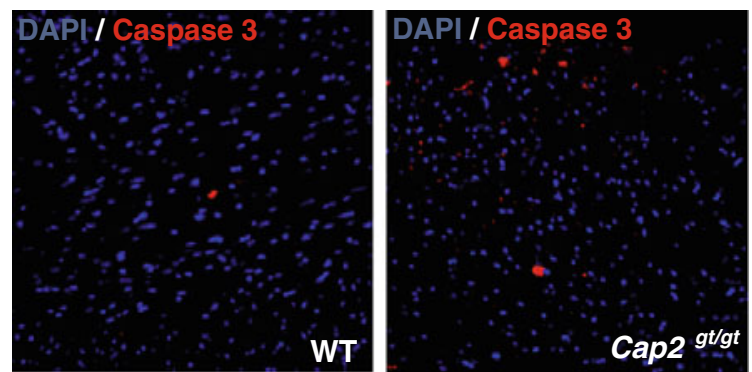

surface ECG showing recordings from 3-month-old WT and Cap $2^{g t / g t}$ mice. h Cap $2^{g t / g t}$ mice have increased myocardial fibrosis. Masson trichrome-stained sections from $\mathrm{Cap}^{\mathrm{gt} / \mathrm{gt}}$ hearts revealed increased fibrosis (blue) in comparison to WT hearts. i H\&E staining of transverse sections through the heart at E13.5 shows no major defects in mutant embryos. $\mathbf{j}$ Mutant mice at $\mathrm{P} 4$ showed severe dilation of atria and mild dilation of ventricle. $\mathbf{k}$ Increased apoptosis in mutant mice visualized by cleaved caspase 3 immunofluorescence. Nuclei were stained with DAPI

Some areas in the ventricles and atrium had well-formed sarcomeres, in other areas the sarcomeric organization was disarrayed. Ventricles and atria appeared equally affected. Double immunofluorescence using desmin (Z-band) and myomesin (M-band) antibodies revealed elongated and 
Table 1 Gross morphological cardiac defects observed in Cap2 $2^{g t / g t}$ mice

\begin{tabular}{lcc}
\hline & Male & Female \\
\hline Ventricular dilation (VD) & 31 & 17 \\
Atrial dilation (AD) with mild VD & 3 & 1 \\
Severe VD and AD & 6 & 4 \\
Total number of mice & 40 & 22 \\
Sudden cardiac death & 32 & 8 \\
\hline
\end{tabular}

Table 2 Surface ECG parameters

\begin{tabular}{lcc}
\hline & WT $(n=9)$ & Cap2 $^{\text {tt/gt }}(n=8)$ \\
\hline Heart rate $(b p m)$ & $445.3 \pm 33.0$ & $403.5 \pm 39.1^{*}$ \\
P (ms) & $14.3 \pm 1.4$ & $15.4 \pm 1.9$ \\
PQ (ms) & $39.0 \pm 6.3$ & $45.4 \pm 3.6^{*}$ \\
QRS $(\mathrm{ms})$ & $12.7 \pm 1.5$ & $15.0 \pm 1.7^{* *}$ \\
QT $(\mathrm{ms})$ & $30.7 \pm 3.0$ & $35.3 \pm 3.9^{*}$ \\
QTc $(\mathrm{ms})$ & $26.4 \pm 2.6$ & $28.9 \pm 3.4$ \\
\hline
\end{tabular}

QTc rate corrected $\mathrm{QT}$ time

well-organized sarcomeres in WT mice, whereas in $\mathrm{Cap}^{\mathrm{gt} / \mathrm{gt}}$ mice the M-line was severely disturbed as we could not observe a well-formed M-line as detected by myomesin in many areas of the cardiac sections (Fig. 5a). In heart specimens from the mutant we also saw a striated staining pattern for desmin, alpha-actinin, and troponin-I, however, it was frequently irregular, and in addition we detected areas with deposition of desmin aggregates as observed in desminopathies [25]. Aggregate-like structures were also seen when we stained for troponin-I. Consistent with this, we also noted disorganized sarcomeres in mutant skeletal muscle when compared to WT (data not shown). The intercalated discs as visualized by connexin 43 labeling appeared not to be dramatically altered at this level of resolution (Fig. 5b).

Consistent with our confocal analysis, examination by electron microscopy revealed severe disarray of sarcomeres in ventricular myocardium of $\mathrm{Cap} 2^{g t / g t}$. In WT ventricular myocardium, the sarcomeres showed clearly defined A- and I-bands and Z-discs and M-lines. In Cap $2^{g t / g t}$ mice, the length of the sarcomeres appeared reduced with the M-lines and I-bands almost indistinguishable. The overview at lower magnification illustrates the reduced number of myofibrils in heart muscle cells as well as the missing of the dark zone and the narrowed banding pattern (Fig. 5c).

Passive and active mechanical properties of myofibrils

To determine whether the dilated cardiomyopathy induced by the lack of CAP2 results from altered mechanical properties or from impaired contractile function of the sarcomeres, the passive, active, and kinetic force-generating properties of myofibrils isolated from $\mathrm{Cap}^{\text {gt/gt }}$ and WT hearts were investigated (two males and one female were used from each genotype).

When compared to the corresponding WT control, the slack sarcomere length $\left(\mathrm{SL}_{0}\right)$ is significantly reduced $(p<0.05)$ in left ventricular myofibrils and highly significantly reduced $(p<0.01)$ in right ventricular myofibrils from Cap2 $2^{\text {gt/gt }}$ mice (Fig. 6a).

Figure $6 \mathrm{~b}$ and $\mathrm{c}$ show relations of the passive tension $\left(F_{\text {pass }}\right)$ measured at relaxing $\left[\mathrm{Ca}^{2+}\right]$ (pCa 7$)$ on the sarcomere length (SL). The lines in the figures represent the best fit of the worm-like chain model of entropic elasticity [26] to the experimental $F_{\text {pass }}-\mathrm{SL}$ data points (Fig. $6 \mathrm{~b}, \mathrm{c}$ ). At $\mathrm{SL} \geq 2.1 \mu \mathrm{m}$, the experimental and the modeled $F_{\text {pass }}-\mathrm{SL}$ relation of left and right ventricular myofibrils from $\mathrm{Cap} 2^{\text {gt/gt }}$ mice are shifted upwards compared to the corresponding WT relation. Thus, in myofibrils lacking CAP2, a higher tension is required for stretching the myofibril to a certain SL than in WT myofibrils.

Force development kinetics were studied in two ways: (1) by rapidly increasing the $\left[\mathrm{Ca}^{2+}\right]$ from $\mathrm{pCa} 7-4.5$ yielding the rate constant $k_{\mathrm{ACT}}$ of $\mathrm{Ca}^{2+}$-induced force development, and (2) by applying a mechanical shortening-restretch maneuver yielding the rate constant $k_{\mathrm{TR}}$ of tension redevelopment that reports cross-bridge turnover kinetics during steady-state $\mathrm{Ca}^{2+}$-activation. Neither $k_{\mathrm{ACT}}$ nor $k_{\mathrm{TR}}$ was significantly altered in CAP2-deficient myofibrils compared to WT (Table 3). Myofibrillar relaxation kinetics was induced by rapidly reducing the $\left[\mathrm{Ca}^{2+}\right]$ from pCa 4.5-7. Upon $\left[\mathrm{Ca}^{2+}\right]$-reduction, the force decays biphasically, starting with a slow linear phase with the rate constant $k_{\mathrm{LIN}}$ that lasts for a time $t_{\text {LIN }}$ whereupon force decays by a fast, mono-exponential relaxation phase with the rate constant $k_{\mathrm{REL}}$. None of the three relaxation parameters exhibited significant differences between myofibrils from $\mathrm{Cap} 2^{g t / g t}$ and WT mice (Table 3), suggesting that sarcomeric relaxation in the myofibrils, which appeared morphologically intact, is not grossly changed.

The force-pCa relations of myofibrils isolated from the left and the right ventricle of $\mathrm{Cap} 2^{g t / g t}$ mice were slightly shifted to the right compared to the corresponding relation of the WT control, indicating a slight decrease in the $\mathrm{Ca}^{2+}$. sensitivity of force development in the CAP2-deficient mice (Fig. 6d, e). Moreover, the Hill coefficient reflecting the overall cooperativity of the force-pCa relation was significantly reduced in myofibrils from right ventricles of Cap ${ }^{{ }^{t t / g t}}$ mice (Fig. 6f). Taken together, CAP2 ablation led to reduced sarcomere length, altered passive mechanical properties, and reduced cooperativity of $\mathrm{Ca}^{2+}$-regulated force development of right ventricular myofibrils. 

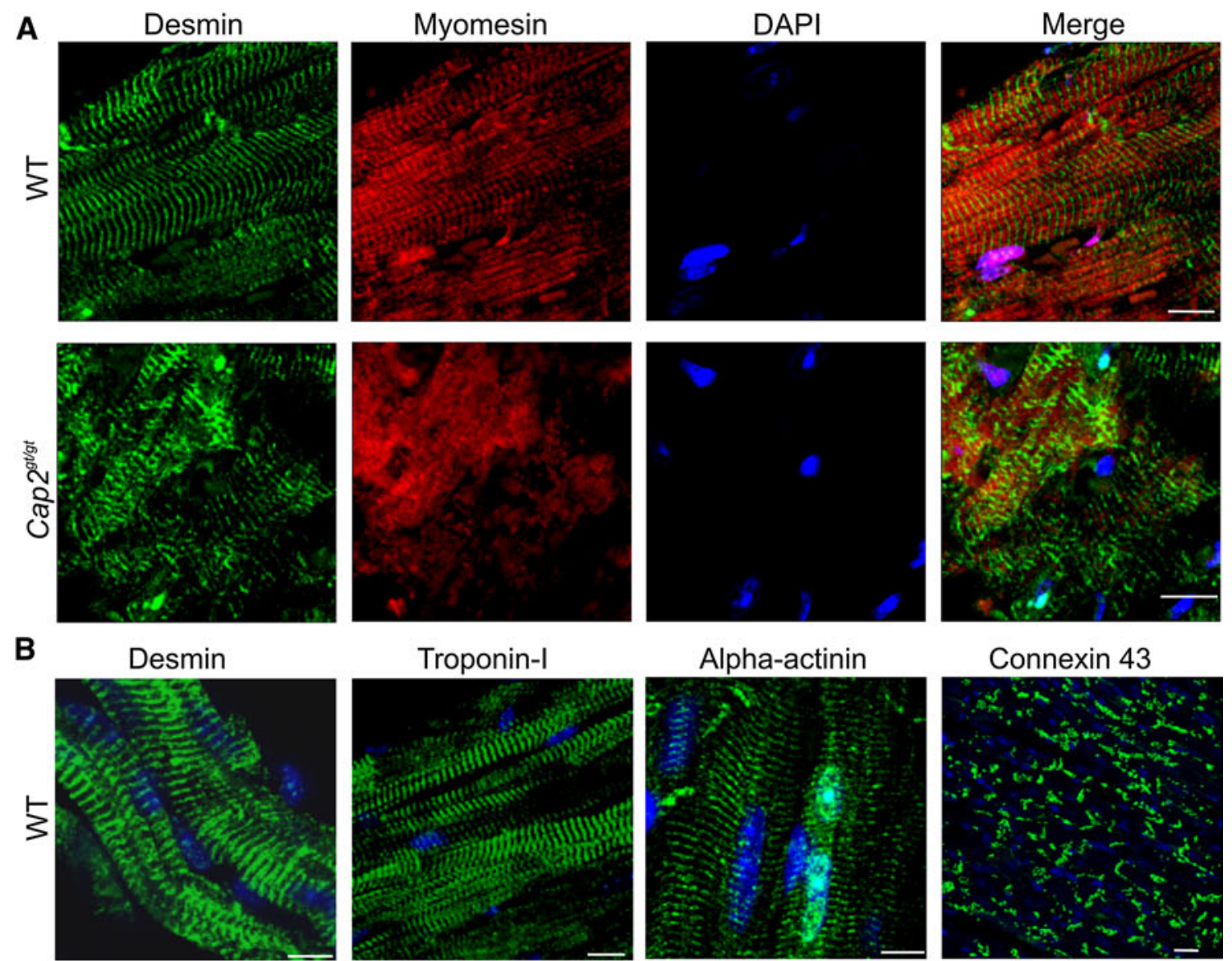

\section{Connexin 43}
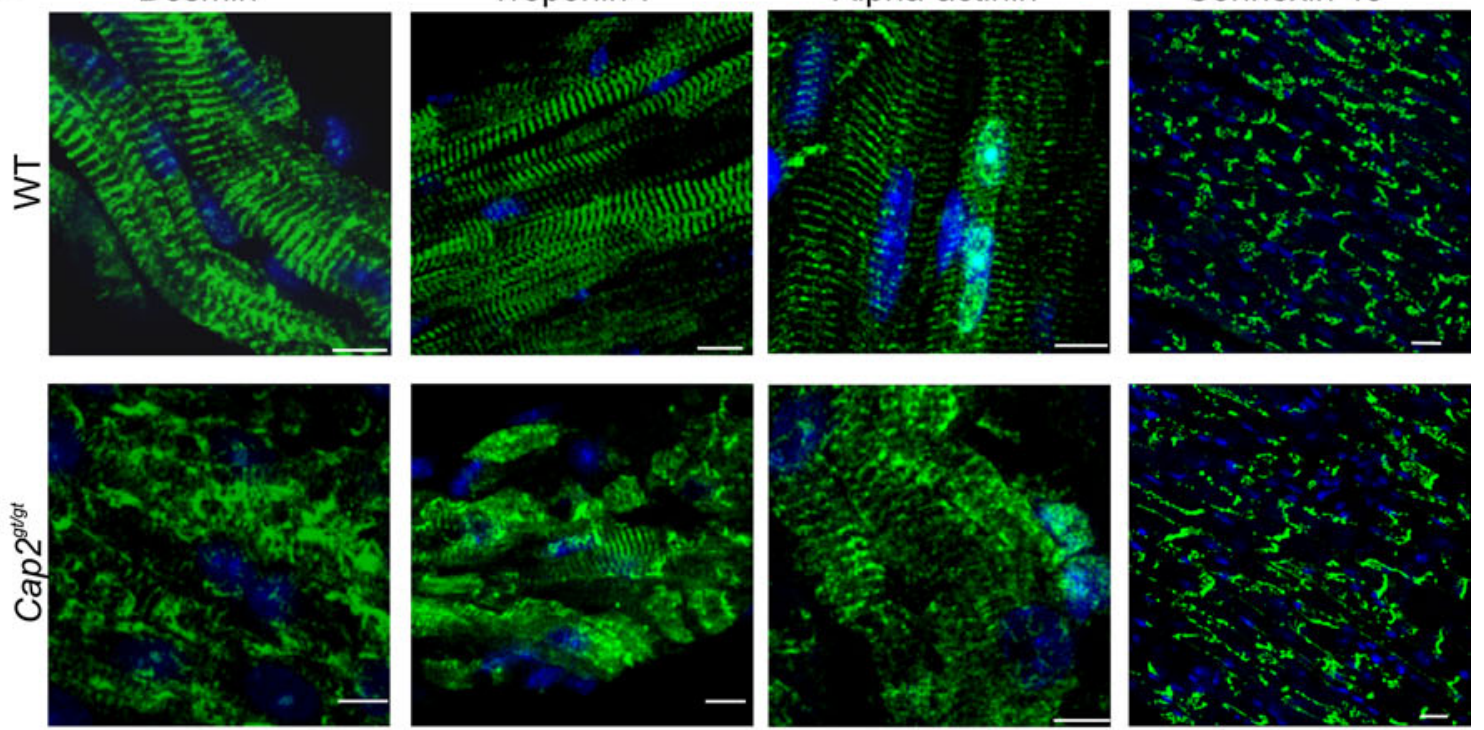

C

Cap2 $2^{g t g t}$
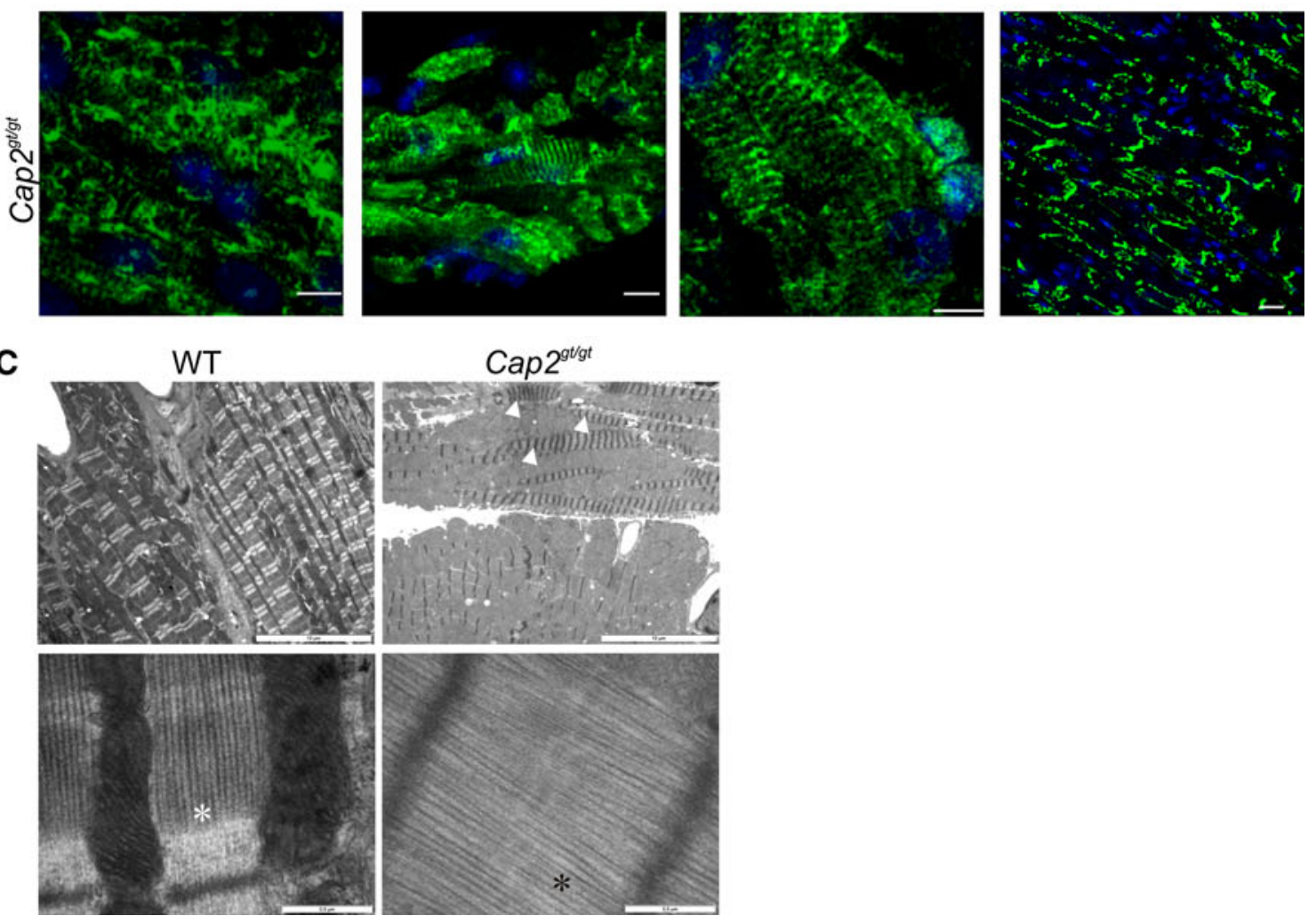
4 Fig. 5 a-c Disarray of sarcomeric organization in $\mathrm{Cap}^{g t / g t}$ mice. a Paraffin-embedded sections stained with desmin (Z-disc) and myomesin (M-line)-specific antibodies showing a compromised and disorganized sarcomeric organization in $\mathrm{Cap}^{\text {gt/gt }}$ mice compared to its WT littermate. b Staining for desmin, alpha-actinin, cardiac troponin-I, and connexin 43 with monoclonal antibodies revealed chaotic organization with fewer striations in $\mathrm{Cap}^{g t / g t}$ mice when compared to WT. Bar $10 \mu \mathrm{m}$ for $\mathbf{a}, \mathbf{b}$ (connexin 43 panel, bar $20 \mu \mathrm{m}$ ). c Electron micrographs of the right ventricular myocardium showing the aberrations in sarcomere organization in mutant animals. The overview at lower magnification (upper panels) illustrates the reduced number of myofibrils, missing of the dark zone and the narrowed Z-line-banding pattern in the sarcomeres (marked with arrows). Higher magnification revealed disarrangement in sarcomere structure. In mutants, there is only one nearly uniformly structured space between the two Z-lines (bottom row, marked with black asterisk) instead of a dark zone (overlapping actin and myosin, marked with white asterisk) flanked by two light zones of solely actin which is evident in WT. Half of a sarcomere is shown for WT reflecting the size differences. Bar $10 \mu \mathrm{m}$ upper panel; $0.5 \mu \mathrm{m}$ lower panel

\section{CAP2 and F-actin dynamics}

An actin association of CAP2 has been addressed previously and it was shown that the C-terminal half of CAP2 shows G-actin sequestering activity [17]. Here we identify a WH2 domain in CAP2 and show that it mediates the actin sequestering activity of the protein. The WH2 domain was identified in a comparison with N-WASP and thymosin $\beta 4$. It is located at position $247-310$ and contains the essential LRHV motif and a N-terminal helix preceding this motif [27] (Fig. 7e). We generated various CAP2 fusion proteins corresponding to individual domains (Fig. 7a), characterized their interaction with G-actin, and compared it to the one of the full-length proteins. In actin polymerization assays, we found that full-length CAP2 (Fig. 7b), a polypeptide encompassing the $\mathrm{WH} 2$ domain and the $\mathrm{C}$ terminal part (WH2-CCAP2; Fig. 7c), and the WH2 domain (Fig. 7d) exhibited a G-actin sequestering activity whereas the $\mathrm{C}$-terminal domain lacking the $\mathrm{WH} 2$ domain $(\Delta \mathrm{WH} 2$ CCAP2) did not show any activity (data not shown). Therefore, we conclude that the actin-sequestering activity of CAP2 resides in the $\mathrm{WH} 2$ domain. This domain could also disrupt preformed actin filaments (Fig. 7f; Supplemental movie). A similar activity has been described for Spire WH2 domains [28].

To address the oligomerization potential of CAP2 gel filtration column chromatography was carried out. The

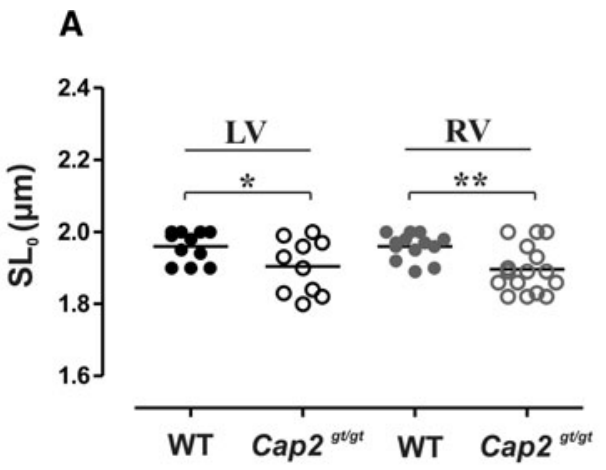

D

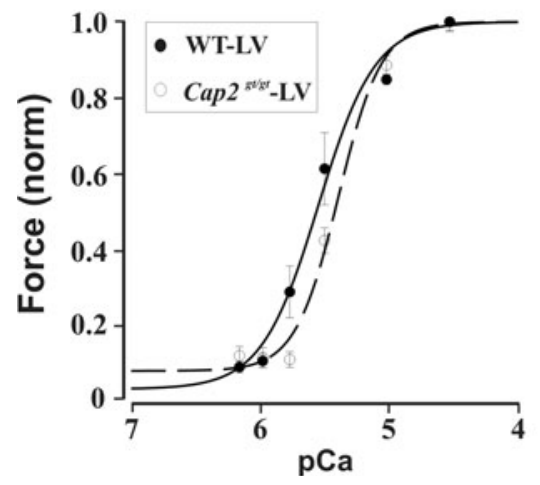

Fig. 6 a-f Passive elastic properties of myofibrils from right and left ventricles of WT and Cap2 $2^{\text {gt/gt }}$ mice measured under relaxing conditions ( $\mathrm{pCa} 7$ ). a Sarcomere length of myofibrils measured while they were slack. Horizontal lines indicate mean values, $n$ number of measured myofibrils. b, c Steady-state passive force measured by stretching myofibrils isolated from left (b) or right (c) ventricles to
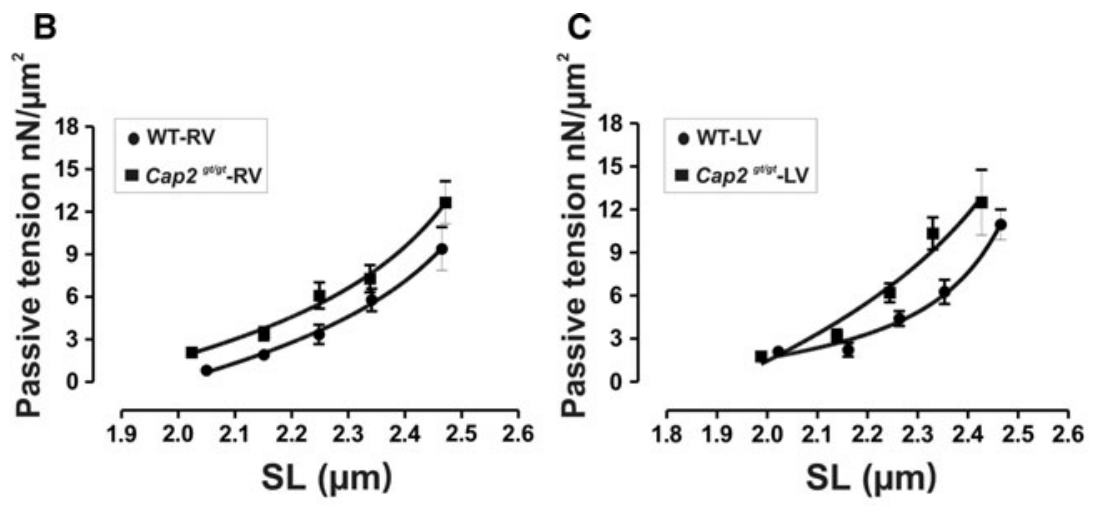

$\mathbf{F}$
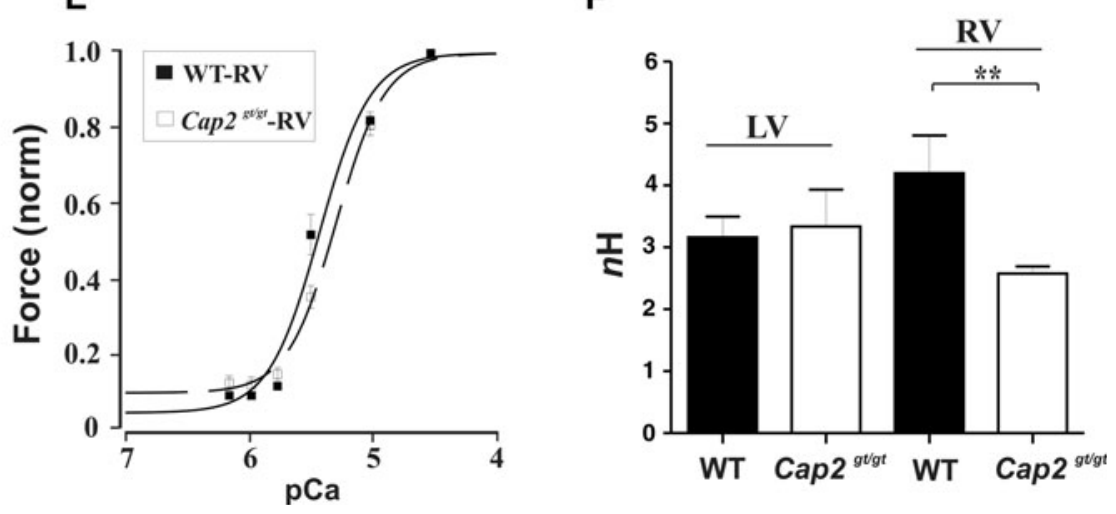

different sarcomere lengths. Data are fitted to the worm-like chain model of entropic elasticity. d, e, Force-pCa relations of myofibrils from the left (d) and right (e) ventricle of WT (filled symbols) and Cap2 ${ }^{\text {gt/gt }}$ mice (open symbols). f The Hill coefficient is highly significantly $(p<0.01)$ reduced in right ventricular myofibrils from Cap2 ${ }^{\text {gt/gt }}$ mice. All data are mean \pm SEM of 8-12 myofibrils 
Table 3 Steady-state and kinetic force parameters of myofibrils isolated from right and left ventricles of WT and Cap $2^{\text {gt/gt }}$ mice

\begin{tabular}{lllll}
\hline & WT-LV & KO-LV & WT-RV & KO-RV \\
\hline$S L_{0}(\mu \mathrm{m})$ & $1.960 \pm 0.013$ & $1.904 \pm 0.024$ & $1.960 \pm 0.010$ & $1.896 \pm 0.016$ \\
& $(n=11)$ & $(n=10)^{*}$ & $(n=13)$ & $(n=16)^{* *}$ \\
$F_{\text {max }}\left(\mathrm{nN} / \mu \mathrm{m}^{2}\right)$ & $90 \pm 13$ & $70 \pm 9$ & $85 \pm 11$ & $82 \pm 6$ \\
& $(n=8)$ & $(n=7)$ & $(n=8)$ & $(n=14)$ \\
$p C a_{50}$ & $5.48 \pm 0.1$ & $5.38 \pm 0.03$ & $5.43 \pm 0.05$ & $5.29 \pm 0.03$ \\
& $(n=8)$ & $(n=9)$ & $(n=10)$ & $(n=12)$ \\
$\mathrm{n}_{\mathrm{H}}$ & $3.16 \pm 0.33$ & $3.34 \pm 0.60$ & $4.19 \pm 0.61$ & $2.57 \pm 0.12$ \\
& $(n=8)$ & $(n=9)$ & $(n=10)$ & $(n=12)^{* *}$ \\
$k_{\mathrm{ACT}}\left(\mathrm{s}^{-1}\right)$ & $4.57 \pm 0.24$ & $4.70 \pm 0.28$ & $4.48 \pm 0.18$ & $4.24 \pm 0.20$ \\
& $(n=17)$ & $(n=17)$ & $(n=23)$ & $(n=20)$ \\
$k_{\mathrm{TR}}\left(\mathrm{s}^{-1}\right)$ & $6.72 \pm 0.43$ & $6.45 \pm 0.34$ & $7.26 \pm 0.34$ & $6.26 \pm 0.36$ \\
& $(n=17)$ & $(n=16)$ & $(n=24)$ & $(n=19)$ \\
$k_{\mathrm{LIN}}\left(\mathrm{s}^{-1}\right)$ & $2.22 \pm 0.16$ & $2.02 \pm 0.33$ & $2.36 \pm 0.20$ & $2.01 \pm 0.23$ \\
& $(n=16)$ & $(n=13)$ & $(n=25)$ & $(n=19)$ \\
$t_{\mathrm{LIN}}(\mathrm{ms})$ & $50 \pm 3$ & $44 \pm 4$ & $44 \pm 2$ & $47 \pm 3$ \\
& $(n=16)$ & $(n=13)$ & $(n=25)$ & $(n=19)$ \\
$k_{\mathrm{REL}}\left(\mathrm{s}^{-1}\right)$ & $28.50 \pm 1.33$ & $30.43 \pm 2.07$ & $33.26 \pm 1.16$ & $31.11 \pm 1.37$ \\
& $(n=16)$ & $(n=14)$ & $(n=23)$ & $(n=19)$ \\
\hline & & & &
\end{tabular}

$\mathrm{N}$-terminal domain eluted in fractions corresponding to a dimer and a monomer (70 and $35 \mathrm{kDa})$, the $\mathrm{WH} 2$ domain alone existed in three different populations from monomer to trimer (Fig. $7 \mathrm{~g}, \mathrm{~h}$ ) and the C-terminal domain was present as a dimer at $50 \mathrm{kDa}$ (Fig. 7i). Taken together, our gel filtration data suggest that CAP2 has the potential to form dimers or trimers and this property may be necessary for its in vivo role.

\section{Discussion}

In the current study, we generate mice lacking CAP2 using a gene-trap approach, which inactivates the protein nonconditionally. For the first time, we show that deletion of CAP2 leads to DCM and dilation of the atria, which eventually results in severe dilation of all the four chambers with age. Although Cap2 is detected at stages E7.5, E8.5, and E9.5 by whole-mount in situ hybridization in the heart, suggesting that it is expressed during cardiogenesis, the CAP2-deficient mice did not exhibit obvious apparent morphological changes in the embryonic heart. CAP2 deletion is lethal in postnatal stages. Most of the deaths in the mutant mice were from sudden cardiac death. Given the fact that there are severe conduction delays, reentry tachyarrhythmia is possible. Our hypothesis is that the severe cardiomyopathy that these mice developed led to various arrhythmias like ventricular tachycardia and ventricular fibrillation, which caused the sudden cardiac death. These possibilities must be studied further. We know from human studies that the patients with dilated cardiomyopathy have a high rate of annual mortality of 5-10 \% despite having the best medical treatment. Sudden death is accounted for in over $50 \%$ of these deaths, most often due to rapid ventricular tachycardia and ventricular fibrillation [29].

The presence of apoptosis and fibrosis in the $\mathrm{Cap} 2^{g t / g t}$ mice suggested that there was an early cell death in the myocardium. This cell death was mostly uniformly spread in the myocardium and not related to any particular vessel territory, which points toward genetically programed cell death rather than being ischemia-related. Increased apoptosis was more prominent in failing hearts and in hearts, which had already developed DCM. Whereas a link between CAP and apoptosis has been established for CAP1 and yeast $\mathrm{CAP}$, such a connection has not been investigated for CAP2 and it is unclear at present what the underlying mechanism might be $[15,30]$. One possibility is that genes in the surroundings of the Cap2 locus are affected in their activity by the genetic manipulation. Of interest in this context is the Rnf144b gene located in the immediate vicinity of Cap2. Rnf144b encodes an IBR-type E3 ubiquitin ligase, a gene that is implicated in apoptosis [31]. Further investigations are needed considering the emerging importance of genome-regulatory blocks.

A further finding of our study is that mortality due to DCM and atrial dilation is more evident in male than female animals. The cardiac dilation and thinning of the myocardium relative to the chamber area are remarkably similar to those observed in histomorphometric analyses of biopsy samples from human dilated cardiomyopathy [32, 33]. In most of these cases, the heart exhibited an increased 
Fig. 7 a-e Inhibition of actin polymerization by CAP2. a Schematic representation of various CAP2 polypeptides that were used in actin polymerization assays. b Actin polymerization can be inhibited by the addition of CAP2. The assays were done with $2 \mu \mathrm{M}$ actin, $10 \%$ pyrene-labeled. Blue, control, actin only. Fast degradation of the large fusion proteins allowed only the measurement of qualitative activities (GST CAP2 ${ }_{\mathrm{FL}}$ : $1.3 \mathrm{mg} / \mathrm{ml}$; $\mathrm{CAP} 2_{\mathrm{FL}}$ : $0.06 \mathrm{mg} / \mathrm{ml}$; CAP2 ${ }_{56-476}$ : $0.5 \mathrm{mg} / \mathrm{ml}$ ). c, d The WH2 domain is responsible for inhibition of actin polymerization. The amount of CAP2 polypeptides is indicated; polymerization was monitored over the time indicated.

$\triangle$ WH2-CCAP2 lacking the WH2 domain had no effect on actin polymerization.

e Comparison of $\mathrm{WH} 2$ domains. The N-terminal helix, the LRHV motif and further highly conserved residues are boxed. GenBank accession numbers are Ms_CAP1, CAM18197;

Hs_CAP1, CAG33690;

Ms_CAP2, NP_080332.1;

Hs_CAP2, CAG33303;

Ms_N-WASP, CAC69994;

Ms_TB4, NP_067253.

f WH2-induced fragmentation of actin filaments. A Alexa Fluor 488 labeled F-actin/fascin bundles bound to NEM-HMM at the beginning of the experiment. $\left(B, B^{\prime}\right)$ Disruption of the filaments after addition of CAP2 WH2 domain. Note that the filaments are not just depolymerizing from their ends but show randomly distributed gaps all over the filament (arrowheads in $B^{\prime}$ ), indicating the fragmenting activity of the WH2 domain (see Supplemental movie 1)
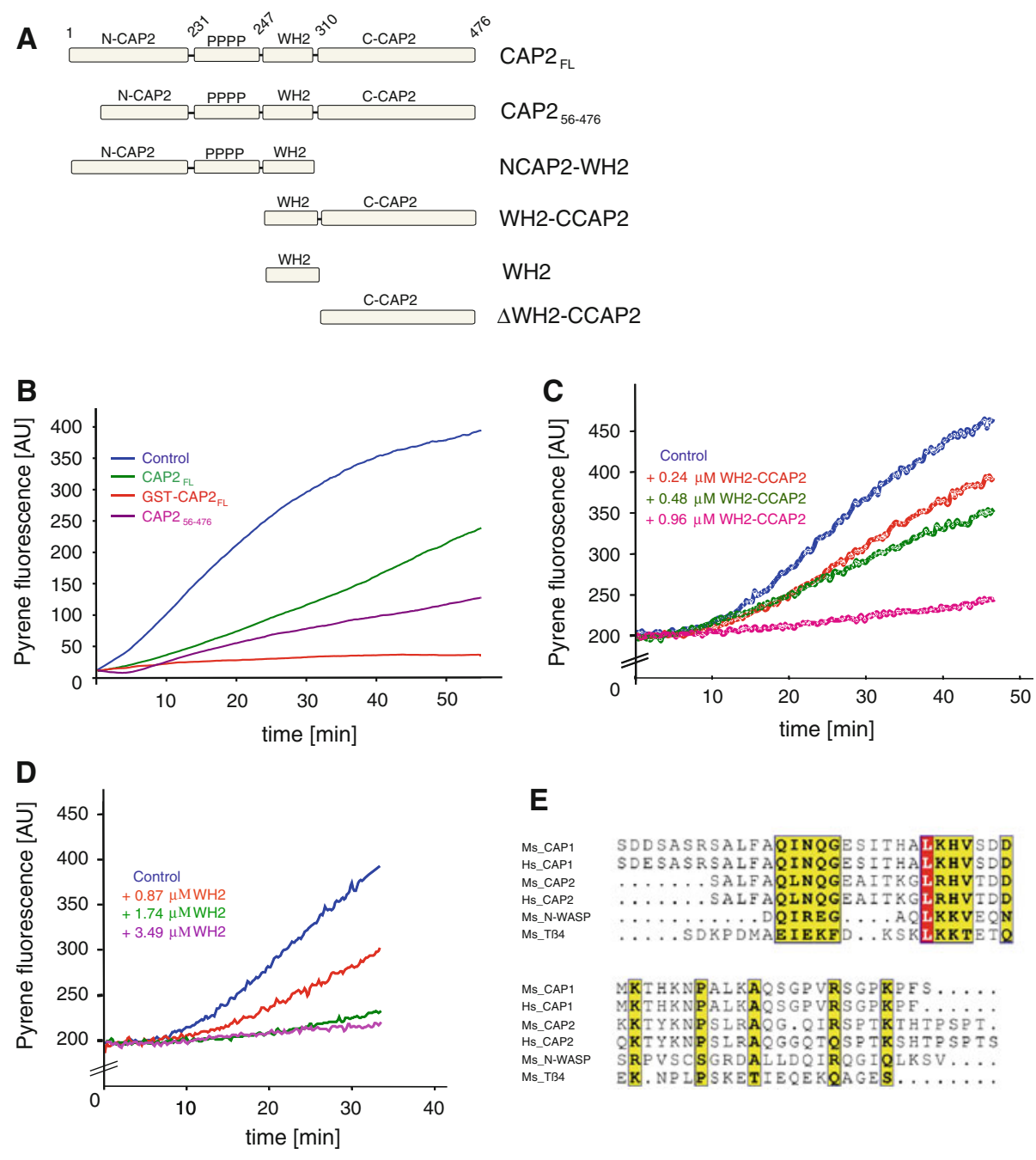

F
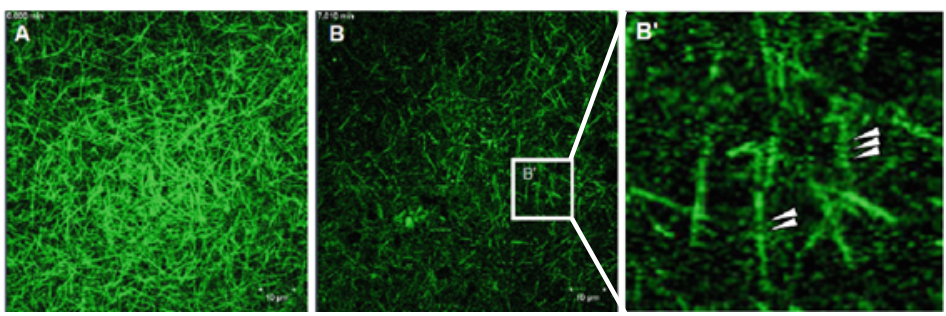

G H

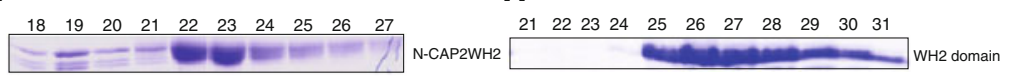

I

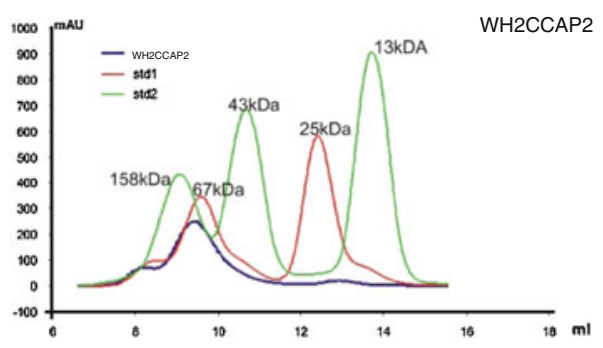


weight relative to the body, wall thinning, and chamber dilatation similar to the pathological alterations observed in $\mathrm{Cap} 2^{\mathrm{gt} / \mathrm{gt}}$ mice. The human CAP2 gene is present on chromosome 6, specifically at 6p22.3. Davies et al. [34] reported a new interstitial $6 \mathrm{p} 22-24$ deletion syndrome after finding several cases with this type of deletion. The patients studied showed various cardiac defects along with other developmental abnormalities. In recent work, Bremer et al. [35] mapped and narrowed down the critical region for the $6 \mathrm{p} 22$ deletion phenotype to $2.2 \mathrm{Mb}$ and found the human CAP2 gene in this locus. As the patients were haploinsufficient for the deletion it might be that the amount of protein needed for physiological cardiac functioning was inadequate. Consistent with the findings in human, we also observed mild dilation of the heart in the heterozygous situation while in the homozygous situation these mice developed DCM. To support this hypothesis further, the involvement of CAP2 in human DCM patients needs to be addressed.

In our studies, we observed that DCM developed in both female and male mutant mice, but mortality was more pronounced in male mice than females. This is in accordance with previous studies showing that female sex protects against the severity and frequency of DCM [36, 37]. Many studies in a number of mouse strains revealed multiple differences between male and female animals. Transgenic overexpression of phospholamban, TNF- $\alpha$, $\beta 2 \mathrm{AR}, \mathrm{NCX}$ showed a gender-related discrepancy in the cardiac phenotype in which the more severe phenotype was observed in males [38-41]. Similarly, gene disruption of FKBP12.6, phospholamban, and ER $\alpha$ revealed a cardiac phenotype with male preponderance [42-44]. Studies with patients hospitalized for acute heart failure in the EuroHeart Failure Survey II revealed that men had DCM more frequently than women [45]. The exact molecular mechanism is still unknown, but the hypothesis is that estrogen prevents the development of cardiovascular diseases that could culminate into CHF [37]. However, this was challenged by the findings that estrogen replacement in postmenopausal women actually increased heart disease [46]. Thus, our Cap2 gene-trap model may serve as a good addition to current DCM models to understand the molecular basis of DCM and sex differences in DCM progression.

Dilated cardiomyopathy is characterized by structural abnormalities that affect myocardial activation and mechanical contraction [47]. The electrical impulse propagation may be delayed concomitant to pathological involvement of the conduction system or due to inhomogeneous spread of excitation wavefronts across scarred tissue [48]. Consistent with our results of the X-Gal staining that showed a high level of CAP2 expression in both atrial and ventricular tissue, we demonstrated significant prolongations in atrial as well as ventricular conduction times in $\mathrm{Cap}^{g t / g t}$. Furthermore, we found a drastic reduction in the basal heart rate in the mutant mice that might point towards a pathological involvement of sinus node function. CAP2 expression at high levels in all major sites of the heart points to a general role of CAP2 in the physiology of the cardiac system. Young Cap $2^{g t / g t}$ mice exhibit DCM, thinning of ventricular wall, atrial dilation, and structural cardiac defects. Later on, with ageing, the whole heart is severely affected, leading to the dilation of all four chamber of the heart.

The sarcomere consists of the Z-disc, A-bands, and M-line. Organization of each of these structures is essential for proper functioning of the sarcomere and their perturbation can lead to malfunctioning of cardiac tissue. Several studies have linked cytoskeletal proteins to cardiomyopathy such as the Z-disc proteins ALP and ZASP/cypher [49, $50]$, the membrane-associated cytoskeletal proteins dystrophin [51] and sarcoglycans [52], and the intermediate filament component desmin [53].

The M-band proteins myomesin and C-protein crosslink the thick filament system (myosins) and the M-band part of titin, the component of the elastic filaments. Thus, the impairment of the M-band structure and its consequence on overall sarcomere organization could be a key event during development of dilated cardiomyopathy. A muscle LIM protein knockout mouse (MLP-KO) and a transgenic mouse with stabilized $\beta$-catenin in the heart progressively develop a severe DCM phenotype and result in heart failure and premature death $[54,55]$. Interestingly, in both of these DCM models, myomesin and M-protein expression were altered. DCM samples from human also confirmed the upregulation of myomesin [56]. Such an increase was related to remodeling and hypothesized as a general adaptation to the altered contractile mechanics of the sarcomere in the dilated heart. An indirect approach where transcription factor Mef2c was knocked out in a skeletal muscle-specific manner, led to drastic reduction of myomesin and a disorganization of sarcomeres [57]. There is still no myomesin knockout mouse available that could address the in vivo function of this protein family. We study a further M-band protein, CAP2 [17], and show that its ablation leads to ventricular DCM clearly indicating its necessity at the M-band and its effect on sarcomere organization.

Myofibrillar organization is important in physiological functioning of the cardiac system. The turnover of the entire actin filaments in myofibrils is not completely understood, and it is reported to be slow [8]. The sarcomeric actin filaments are very stable in non-contractile cells, whereas contractility induces rapid depolymerization of the non-productive filaments [9]. These may be subsequently replaced by rapid actin filament nucleation [8]. 


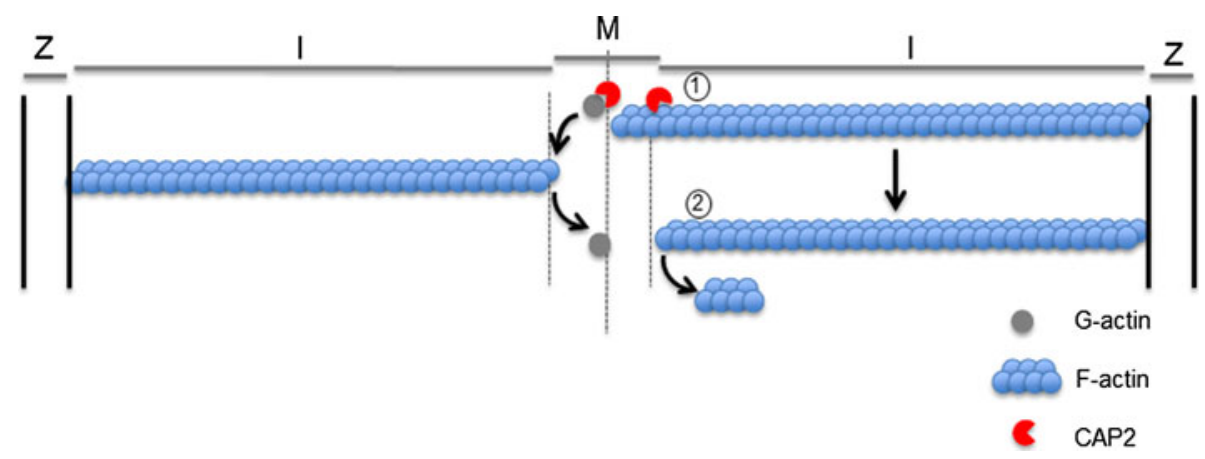

Fig. 8 Model illustrating CAP2 function in cardiac muscle. CAP2 localizes to the M-band and adjacent regions of the sarcomere. Upon formation of F-actin in the sarcomere (1), the length of the filament is maintained through severing activity of CAP2 through its WH2

CAP2 is present in the relevant area of the sarcomere to regulate filament formation [17] and our data show that lack of CAP2 leads to a disarray of the sarcomere, presumably due to the loss of its G-actin sequestering and filament-fragmenting activity.

Even though right heart failure is most often a consequence of the left ventricular dysfunction in a diffuse myocardial disease, right ventricular failure might develop before the left ventricular failure [2]. Right ventricular dilation is one of the critical issues that could lead to lifethreatening arrhythmia. Clinical studies pertaining to right ventricular abnormalities show a common trend of $\mathrm{RV}$ dilation in certain groups [58]. Although many clinical studies in human patients point out the severity and detrimental effects of dilation of RV and/or RV-DCM, its exact causes on the genetic level and its governing mechanisms are poorly understood. Interestingly, CAP2 deficiency reduces the cooperativity of calcium-regulated force development in right ventricular myofibrils, which might indicate that impaired cooperative activation of the regulatory troponin-tropomyosin units on the actin filament is a primary dysfunction associated to the development of DCM in CAP2-deficient mice. CAP2 might be one of the important genes that could be indispensable for physiological heart functioning in humans, an issue that must be addressed further.

In summary, our studies demonstrate that CAP2 is essential for physiological functioning of the cardiac system and a deficiency leads to DCM and various cardiac defects. At the ultrastructural level, ablation of CAP2 leads to disarray of the sarcomere and abnormalities in electrical conduction in cardiac tissue. Moreover, mechanical properties of myofibrils are affected with a drastic reduction in the cooperativity of calcium-regulated force development. At the subcellular level, CAP2 regulates actin dynamics by binding to G-actin through its WH2 domain, preventing polymerization and also severing of F-actin, thereby domain (2). Moreover, through its G-actin sequestering activity, which resides in the $\mathrm{WH} 2$ domain, it also maintains the pool of $\mathrm{G}$-actin in the sarcomere. $I \mathrm{I}$-band, $M$ M-line, $Z \mathrm{Z}$-band

affecting filament stability, and these activities might be vital for the structural integrity of the sarcomere as proposed in the model (Fig. 8).

Acknowledgments ES cells and mice were obtained from the EUCOMM consortium, Helmholtz Zentrum München, Munich, Germany. We thank Daniela Rieger for the preparation of actin and Rolf Müller for protein purification. MS is supported by the Deutsche Forschungsgemeinschaft (SFB 863, SFB 914), GP by SFB 612, JG by the Elite Network of Bavaria. BB and KK are supported by the IGSDHD.

\section{References}

1. Jefferies JL, Towbin JA (2010) Dilated cardiomyopathy. Lancet 27:752-762

2. Fitchett DH, Sugrue DD, Macarthur CG, Oakley CM (1984) Right ventricular dilated cardiomyopathy. Br Heart J 51:25-29

3. Ibsen HH, Baandrup U, Simonsen EE (1985) Familial right ventricular dilated cardiomyopathy. Br Heart J 54:156-159

4. Mann DL, Urabe Y, Kent RL, Vinciguerra S, Cooper G IV (1991) Cellular versus myocardial basis for the contractile dysfunction of hypertrophied myocardium. Circ Res 68:402-415

5. Schaper J, Froede R, Hein S, Buck A, Hashizume H, Speiser B, Friedl A, Bleese N (1991) Impairment of the myocardial ultrastructure and changes of the cytoskeleton in dilated cardiomyopathy. Circulation 83:504-514

6. Harvey PA, Leinwand LA (2011) The cell biology of disease: cellular mechanisms of cardiomyopathy. J Cell Biol 194:355-365

7. Sussman MA, Welch S, Cambon N, Klevitsky R, Hewett TE, Price R, Witt SA, Kimball TR (1998) Myofibril degeneration caused by tropomodulin overexpression leads to dilated cardiomyopathy in juvenile mice. J Clin Invest 101:51-61

8. Littlefield RS, Fowler VM (2008) Thin filament length regulation in striated muscle sarcomeres: pointed-end dynamics go beyond a nebulin ruler. Semin Cell Dev Biol 19:511-519

9. Skwarek-Maruszewska A, Hotulainen P, Mattila PK, Lappalainen $P$ (2009) Contractility-dependent actin dynamics in cardiomyocyte sarcomeres. J Cell Sci 122:2119-2126

10. Ducka AM, Joel P, Popowicz GM, Trybus KM, Schleicher M, Noegel AA, Huber R, Holak TA, Sitar T (2010) Structures of actin-bound Wiskott-Aldrich syndrome protein homology 2 
(WH2) domains of Spire and the implication for filament nucleation. Proc Natl Acad Sci USA 107:11757-11762

11. Czisch M, Schleicher M, Hörger S, Voelter W, Holak TA (1993) Conformation of thymosin beta 4 in water determined by NMR spectroscopy. Eur J Biochem 218:335-344

12. Noegel AA, Blau-Wasser R, Sultana H, Müller R, Israel L, Schleicher M, Patel H, Weijer CJ (2004) The cyclase-associated protein CAP as regulator of cell polarity and cAMP signaling in dictyostelium. Mol Biol Cell 15:934-945

13. Sultana H, Rivero F, Blau-Wasser R, Schwager S, Balbo A, Bozzaro S, Schleicher M, Noegel AA (2005) Cyclase-associated protein is essential for the functioning of the endo-lysosomal system and provides a link to the actin cytoskeleton. Traffic 6:930-946

14. Bertling E, Hotulainen P, Mattila PK, Matilainen T, Salminen M, Lappalainen P (2004) Cyclase-associated protein 1 (CAP1) promotes cofilin-induced actin dynamics in mammalian nonmuscle cells. Mol Biol Cell 15:2324-2334

15. Wang C, Zhou GL, Vedantam S, Li P, Field J (2008) Mitochondrial shuttling of CAP1 promotes actin- and cofilindependent apoptosis. J Cell Sci 121:2913-2920

16. Christoforou N, Miller RA, Hill CM, Jie CC, Mccallion AS, Gearhart JD (2008) Mouse ES cell-derived cardiac precursor cells are multipotent and facilitate identification of novel cardiac genes. J Clin Invest 118:894-903

17. Peche V, Shekar S, Leichter M, Korte H, Schröder R, Schleicher M, Holak TA, Clemen CS, Ramanath YB, Pfitzer G, Karakesisoglou I, Noegel AA (2007) CAP2, cyclase-associated protein 2, is a dual compartment protein. Cell Mol Life Sci 64:2702-2715

18. Torban E, Patenaude AM, Leclerc S, Rakowiecki S, Gauthier S, Andelfinger G, Epstein DJ, Gros P (2008) Genetic interaction between members of the Vangl family causes neural tube defects in mice. Proc Natl Acad Sci USA 105:3449-3454

19. Eichinger L, Noegel AA, Schleicher M (1991) Domain structure of actin-binding proteins: expression and functional characterization of truncated severin. J Cell Biol 112:665-676

20. Schmoller KM, Semmrich C, Bausch AR (2011) Slow down of actin depolymerization by cross-linking molecules. J Struct Biol 173:350-357

21. Mitchell GF, Jeron A, Koren G (1998) Measurement of heart rate and Q-T interval in the conscious mouse. Am J Physiol 274:H747-H751

22. Stehle R, Krüger M, Scherer P, Brixius K, Schwinger RH, Pfitzer $G$ (2002) Isometric force kinetics upon rapid activation and relaxation of mouse, guinea pig and human heart muscle studied on the subcellular myofibrillar level. Basic Res Cardiol 97:I127I135

23. Stehle R, Krüger M, Pfitzer G (2002) Force kinetics and individual sarcomere dynamics in cardiac myofibrils after rapid $\mathrm{Ca}^{2+}$ changes. Biophys J 83:2152-2161

24. Tamura N, Ogawa Y, Chusho H, Nakamura K, Nakao K, Suda M, Kasahara M, Hashimoto R, Katsuura G, Mukoyama M, Itoh H, Saito Y, Tanaka I, Otani H, Katsuki M (2000) Cardiac fibrosis in mice lacking brain natriuretic peptide. Proc Natl Acad Sci USA 97:4239-4244

25. Fischer D, Clemen CS, Olivé M, Ferrer I, Goudeau B, Roth U, Badorf P, Wattjes MP, Lutterbey G, Kral T, van der Ven PF, Fürst DO, Vicart P, Goldfarb LG, Moza M, Carpen O, Reichelt J, Schröder R (2006) Different early pathogenesis in myotilinopathy compared to primary desminopathy. Neuromuscul Disord 16:361367

26. Linke WA, Fernandez JM (2002) Cardiac titin: molecular basis of elasticity and cellular contribution to elastic and viscous stiffness components in myocardium. J Muscle Res Cell Motil 23:483-497

27. Chereau D, Kerff F, Graceffa P, Grabarek Z, Langsetmo K, Dominguez R (2005) Actin-bound structures of Wiskott-Aldrich syndrome protein (WASP)-homology domain 2 and the implications for filament assembly. Proc Natl Acad Sci USA 102: 16644-16649

28. Sitar T, Gallinger J, Ducka AM, Ikonen TP, Wohlhoefler M, Schmoller KM, Bausch AR, Joel P, Trybus KM, Noegel AA, Schleicher M, Huber R, Holak TA (2011) Molecular architecture of the Spire-actin nucleus and its implication for actin filament assembly. Proc Natl Acad Sci USA 108:19575-19580

29. Grimm W, Maisch B (2002) Sudden cardiac death in dilated cardiomyopathy - therapeutic options. Herz 27:750-759

30. Gourlay CW, Ayscough KR (2006) Actin-induced hyperactivation of the Ras signaling pathway leads to apoptosis in Saccharomyces cerevisiae. Mol Cell Biol 26:6487-6501

31. Benard G, Neutzner A, Peng G, Wang C, Livak F, Youle RJ, Karbowski M (2010) IBRDC2, an IBR-type E3 ubiquitin ligase, is a regulatory factor for Bax and apoptosis activation. EMBO J 21(29):1458-1471

32. Jindal N, Talwar KK, Chopra P (1994) Ultrastructural and histological study of endomyocardial biopsies from patients of dilated cardiomyopathy - a comparative evaluation and their clinical correlation. Indian Heart J 46:329-334

33. Gallo P, D'Amati G, Pelliccia F, Bernucci P, Cianfrocca C, Marino B (1995) Functional significance of myocellular hypertrophy in dilated cardiomyopathy: histomorphometric analysis on 40 endomyocardial biopsies. Am J Cardiovasc Pathol 5:11-18

34. Davies AF, Mirza G, Sekhon G, Turnpenny P, Leroy F, Speleman F, Law C, van Regemorter N, Vamos E, Flinter F, Ragoussis J (1999) Delineation of two distinct 6p deletion syndromes. Hum Genet 104:64-72

35. Bremer A, Schoumans J, Nordenskjöld M, Anderlid BM, Giacobini M (2009) An interstitial deletion of 7.1 Mb in chromosome band 6 p22.3 associated with developmental delay and dysmorphic features including heart defects, short neck, and eye abnormalities. Eur J Med Genet 52:358-362

36. Kadokami T, Mctiernan CF, Kubota T, Frye CS, Feldman AM (2000) Sex-related survival differences in murine cardiomyopathy are associated with differences in TNF-receptor expression. J Clin Invest 106:589-597

37. Satoh M, Matter CM, Ogita H, Takeshita K, Wang CY, Dorn GW II, Liao JK (2007) Inhibition of apoptosis-regulated signaling kinase-1 and prevention of congestive heart failure by estrogen. Circulation 115:3197-3204

38. Dash R, Schmidt AG, Pathak A, Gerst MJ, Biniakiewicz D, Kadambi VJ, Hoit BD, Abraham WT, Kranias EG (2003) Differential regulation of $\mathrm{p} 38$ mitogen-activated protein kinase mediates gender-dependent catecholamine-induced hypertrophy. Cardiovasc Res 57:704-714

39. Kadokami T, Mctiernan CF, Kubota T, Frye CS, Feldman AM (2000) Sex-related survival differences in murine cardiomyopathy are associated with differences in TNF-receptor expression. J Clin Invest 106(4):589-597

40. Cross HR, Murphy E, Koch WJ, Steenbergen C (2002) Male and female mice overexpressing the $\beta_{2}$-adrenergic receptor exhibit differences in ischemia/reperfusion injury: role of nitric oxide. Cardiovasc Res 53:662-671

41. Cross HR, Lu L, Steenbergen C, Philipson KD, Murphy E (1998) Overexpression of the cardiac $\mathrm{Na}^{+} / \mathrm{Ca}^{2+}$ exchanger increases susceptibility to ischemia/reperfusion injury in male, but not female, transgenic mice. Circ Res 83:1215-1223

42. Xin HB, Senbonmatsu T, Cheng DS, Wang YX, Copello JA, Ji GJ, Collier ML, Deng KY, Jeyakumar LH, Magnuson MA, Inagami T, Kotlikoff MI, Fleischer S (2002) Oestrogen protects FKBP12.6 null mice from cardiac hypertrophy. Nature 416(6878): 334-338

43. Cross HR, Kranias EG, Murphy E, Steenbergen C (2003) Ablation of PLB exacerbates ischemic injury to a lesser extent in 
female than male mice: protective role of NO. Am J Physiol Heart Circ Physiol 284:H683-H690

44. Johnson BD, Zheng W, Korach KS, Scheuer T, Catterall WA, Rubanyi GM (1997) Increased expression of the cardiac L-type calcium channel in estrogen receptor-deficient mice. J Gen Physiol 110:135-140

45. Nieminen MS, Harjola VP, Hochadel M, Drexler H, Komajda M, Brutsaert D, Dickstein K, Ponikowski P, Tavazzi L, Follath F, Lopez-Sendon JL (2008) Gender-related differences in patients presenting with acute heart failure. Results from EuroHeart Failure Survey II. Eur J Heart Fail 10(2):140-148

46. Leinwand LA (2003) Sex is a potent modifier of the cardiovascular system. J Clin Invest 112(3):302-307

47. Katz AM (1990) Cardiomyopathy of overload-a major determinant of prognosis in congestive heart failure. N Engl J Med 322:100-110

48. Josephson ME (1993) Intraventricular conduction disturbances. In: Josephson ME (ed) Clinical cardiac electrophysiology: techniques and interpretations. Lea and Febiger, Malvern, pp 117149

49. Hoshijima M, Pashmforoush M, Knoll R, Chien KR (2002) The MLP family of cytoskeletal $\mathrm{Z}$ disc proteins and dilated cardiomyopathy; a stress pathway model for heart failure progression. Cold Spring Harb Symp Quant Biol 67:399-408

50. Zhou Q, Chu PH, Huang C, Cheng CF, Martone ME, Knoll G, Shelton GD, Evans S, Chen J (2001) Ablation of cypher, a POZLIM domain Z-line protein, causes a severe form of \& congenital myopathy. J Cell Biol 155:605-612

51. Megeney LA, Kablar B, Perry RL, Ying C, May L, Rudnicki MA (1999) Severe cardiomyopathy in mice lacking dystrophin and MyoD. Proc Natl Acad Sci USA 96:220-225
52. Durbeej M, Campbell KP (2002) Muscular dystrophies involving the dystrophin-glycoprotein complex: an overview of current mouse models. Curr Opin Genet Dev 12:349-361

53. Milner DJ, Weitzer G, Tran D, Bradley A, Capetanaki Y (1996) Disruption of musclearchitecture and myocardial degeneration in mice lacking desmin. J Cell Biol 134:1255-1270

54. Arber S, Hunter JJ, Ross JJ, Hongo M, Sansig G, Borg J, Perriard JC, Chien KR, Caroni P (1997) MLP-deficient mice exhibit a disruption of cardiac cytoarchitectural organization, dilated cardiomyopathy, and heart failure. Cell 88:393-403

55. Hirschy A, Croquelois A, Perriard E, Schoenauer R, Agarkova I, Hoerstrup SP, Taketo MM, Pedrazzini T, Perriard JC, Ehler E (2010) Stabilised beta-catenin in postnatal ventricular myocardium leads to dilated cardiomyopathy and premature death. Basic Res Cardiol 105:597-608

56. Schoenauer R, Emmert MY, Felley A, Ehler E, Brokopp C, Weber B, Nemir M, Faggian GG, Pedrazzini T, Falk V, Hoerstrup SP, Agarkova I (2011) EH-myomesin splice isoform is a novel marker for dilated cardiomyopathy. Basic Res Cardiol 106:233-247

57. Potthoff MJ, Arnold MA, Mcanally J, Richardson JA, BasselDuby R, Olson EN (2007) Regulation of skeletal muscle sarcomere integrity and postnatal muscle function by Mef2c. Mol Cell Biol 27:8143-8151

58. Foale RA, Nihoyannopoulos P, Ribeiro P, Mckenna WJ, Oakley CM, Krikler DM, Rowland E (1986) Right ventricular abnormalities in ventricular tachycardia of right ventricular origin: relation to electrophysiological abnormalities. Br Heart J 56: $45-54$ 